\title{
Investigation on Mechanical and Microstructure Properties of Steel Fiber Reinforced Concrete
}

\author{
Qinyuan Zhang, Wenwen Xu, Yichen Sun, and Yongcheng Ji \\ College of Civil Engineering, Northeast Forestry University, Harbin 150040, China \\ Correspondence should be addressed to Yongcheng Ji; yongchengji@outlook.com
}

Received 7 November 2021; Revised 16 December 2021; Accepted 17 January 2022; Published 27 February 2022

Academic Editor: Robert Černý

Copyright (c) 2022 Qinyuan Zhang et al. This is an open access article distributed under the Creative Commons Attribution License, which permits unrestricted use, distribution, and reproduction in any medium, provided the original work is properly cited.

\begin{abstract}
This paper studied the microscopic and mechanical property degradation of axially compressed concrete with different steel fiber content under chemical erosion and freeze-thaw environment. Concrete cylinders with three types of steel fiber contents $(0 \%, 1 \%$, $2 \%)$ were selected to study the durability behavior concerning different environmental effects up to 28 days, which included tap water, $3.5 \%$ sodium chloride solution, $10 \%$ sodium sulfate solution, $5 \%$ sulfuric acid solution, 2 mol/L sodium hydroxide solution, and 100 freeze-thaw cycles. The variation of specimens' microstructure and axial bearing capacity with different fiber content was studied with the chemical erosion cycle increase, and the mass and $\mathrm{pH}$ variations of the specimen were measured. According to the law of micro-cracks, the deterioration degree was judged, and a numerical analysis model was established to quantify the reliability of the structure with different fiber content. The results show that the addition of steel fiber can effectively improve the axial bearing capacity of concrete, and a freeze-thaw environment and chemical erosion can accelerate fiber-reinforced concrete's failure. The optimal content of steel fiber was determined, which is $1 \%$ for sodium chloride and sodium sulfate environments, and $2 \%$ for the freeze-thaw cycle, dilute sulfuric acid, and sodium hydroxide environments. The finite element software Abaqus was used to simulate and analyze the freeze-thaw cycle and mechanical test of concrete, which verified the rationality of the test results. Research results will provide a theoretical basis for predicting the performance deterioration of steel fiber reinforced concrete under different erosion conditions and periods.
\end{abstract}

\section{Introduction}

As a primary building material, concrete occupies half of the building structure and road and bridge traffic materials with many advantages such as high strength, easy plasticity, and good economy. However, the defects of ordinary concrete, such as self-weight, low tensile strength, high brittleness, and poor ductility, can no longer meet the use requirements for particular areas and buildings. It has to develop towards higher strength, high toughness, better workability, and better durability. The practical application of fiber-reinforced concrete in structural components has attracted more and more attention due to its structural advantages, such as durability $[1,2]$.

SFRC can effectively improve the compressive strength, shear strength, and splitting tensile strength [3-6]. Fiber concrete has superior performance to ordinary concrete in durability $[7,8]$. Steel fiber exerted a better freeze-thaw resistance than ordinary concrete and effectively delayed the crack propagation and occurrence of macro cracks [9-11]. The longer the fiber length and more extensive the fiber content exerted, the greater the compressive strength, proving that adding steel fiber into concrete showed good freeze-thaw resistance [12-14]. Adding $12 \%$ of fiber into the concrete will damage the mechanical properties of concrete, while excessive addition of fiber will lead to the controlled expansion of concrete cracks and improve the fatigue life of concrete [15]. Freeze-thaw processes lead to frost damage of concrete structures in severe cold areas, and concrete materials often suffer from various chemical attacks, which also significantly impact the durability of concrete structures. The concrete constitutive model was developed using the plastic damage theory and seawater freeze-thaw experiments [16-20]. The compactness of concrete with increased water- 
cement ratio and decreased fly ash content. In addition, an appropriate amount of fiber can improve concrete's chloride ion erosion resistance at an early age [21-23]. Ordinary concrete's physical and chemical properties would be significantly affected, and the durability will worsen when subjected to a sulfate concentration of higher than $5000 \mathrm{mg} /$ L. The crystallization pressure can be explained due to the sodium sulfate decahydrate and crystal morphology transformation [24-26]. The compressive strength of steel fiber reinforced concrete decreases in the acid environment during all exposure periods, and the steel fiber reinforced concrete specimens with all parameters will be deteriorated [27].

Steel fiber can effectively partially or entirely replace the conventional steel bars in nonstructural and structural elements, such as industrial floors, roads and pavements, beams (shear bars) [28-33], slabs [34], and tunnel linings [35], but the optimal fiber content in different environments need to be studied. Fiber-reinforced materials enhance the shear capacity by transferring tensile stress to diagonal cracks and reducing diagonal cracks' spacing and width, thus improving aggregate interlocking. Using diffused steel fiber reinforced materials in concrete can improve the shear performance, and it is possible to replace or reduce conventional shear reinforced materials [36-38]. Most existing design guidelines for steel fiber reinforced concrete (SFRC) members are suitable for members without any conventional reinforcement. If it is to be dealt with, the synergistic effect between steel fiber and traditional steel bar is carried out empirically. In design practice, it is not easy to obtain an analytical model that can be conveniently used to estimate the contribution of fiber to the structural capacity of reinforced concrete members. The meso-model is used to simulate the designed reinforced concrete-steel fiber reinforced concrete beam; the crack width, average crack spacing, deflection, ultimate load, and service load are compared with the design results [39]; and the results have shown that the use of this numerical approach is very appealing to be employed in the design of SFRC structural elements.

There are few comprehensive comparative studies on mechanical properties and durability of steel fiber reinforced concrete with different content under freeze-thaw cycles and various chemical attacks to improve the durability of concrete in a complex environment. This paper studies the mechanical properties of concrete under the influence of various adverse environmental factors by adding steel fibers with different contents and analyzes the deterioration process of microstructure.

\section{Materials and Methods}

The composition materials of the specimen include coarse aggregate, fine aggregate, cement, water, and steel fiber. Coarse aggregate was divided into two particle size zones: $4.75 \mathrm{~mm}$ to $9.5 \mathrm{~mm}, 9.5 \mathrm{~mm}$ to $19 \mathrm{~mm}$, and the mixing ratio was $3: 7$. Natural river sand was selected as fine aggregate. The steel fiber was steel ingot milled steel fiber derived from
Shanghai Harex Technology Co., Ltd. The detailed information is listed as follows: tensile strength is $700 \mathrm{MPa}$, individual length is $32 \mathrm{~mm}$, width is $2.6 \mathrm{~mm}$, the lengthdiameter ratio is 40 , and density is $7850 \mathrm{~kg} / \mathrm{m}$, as shown in Figure 1. Firstly, coarse aggregate and fine aggregate were screened to achieve more accurate results. Secondly, various raw materials were weighed according to the proportion and put into the concrete mixer for 2 minutes of dry mixing, and then cement was added for continuous dry mixing for 1-2 min. Next, weighed water was poured in and stirred for 3-5 minutes after stirring evenly. Finally, the weighed steel fiber was evenly distributed and stirred for 2-5 minutes, and the prepared fiber concrete was added into the mold twice and vibrated for $20-30 \mathrm{~s}$. The vibration rod was inserted and tamped several times to improve the compacting degree in the process of vibration, and the mold was removed and placed into the curing room for 28 days after curing for one day.

The concrete compressive strength of $30 \mathrm{MPa}$ was used, and the water-cement ratio was 0.54 . The steel fiber may cause a slight effect on the water consumption during concrete mixing [40, 41]. Therefore, only the variation of steel fiber content was considered in this test, and the effect of water consumption was ignored. Table 1 shows the concrete mix design.

The volume content of steel fiber in this research was $0 \%$, $1 \%$, and $2 \%$. The size of concrete compressive strength specimens was $150 \mathrm{~mm} \times 150 \mathrm{~mm} \times 150 \mathrm{~mm}$ cube, with three identical specimens in each group to ensure data consistency. The axial compression concrete test specimens used $\Phi 100 \mathrm{~mm} \times 200 \mathrm{~mm}$ cylinders. There are four specimens in each group ( 3 for mechanical test and 1 for microscopic observation). Total 153 samples are used in this experiment, which considered three different steel fiber contents, six different corrosion environments (water, sodium chloride solution, sodium sulfate solution, dilute sulfuric acid solution, sodium hydroxide solution, and freeze-thaw cycle), and two times of erosion. The mean value of the test results was taken as the representative value of the mechanical properties of SFRC. The prepared steel fiber concrete is poured into the mold and cured for 28 days, as shown in Figure 2.

2.1. Experimental Method. According to the "National Standard (Recommended) of the People's Republic of China: Standard for test methods of long-term performance and durability of ordinary concrete" (GB/T 50082-2009)[42], the lab rapid freeze-thaw method was used. Figure 3 shows the KDR-V5 concrete quick freeze-thaw tester used to carry out the freeze-thaw test. The number of freeze-thaw cycles was set as 100 times, and the central temperature of the sample was $-18^{\circ} \mathrm{C} \pm 2^{\circ} \mathrm{C}$ at the end of each freezing cycle. Similarly, the central specimen temperature was $+7^{\circ} \mathrm{C} \pm 2^{\circ} \mathrm{C}$ at the end of the melting cycle. For the chemical erosion test, four erosion mediums were selected, including 3.5\% NaCl solution, $10 \% \mathrm{Na} 2 \mathrm{SO} 4$ solution, $5 \% \mathrm{H} 2 \mathrm{SO} 4$ solution, and $2 \mathrm{~mol} / \mathrm{L}$ of $\mathrm{NaOH}$ solution. The prepared $30 \mathrm{~L}$ solution was poured into a large liquid storage box, and the specimen's 


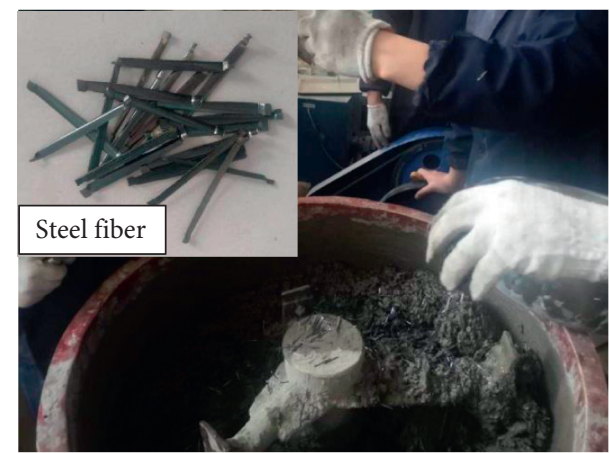

FIGURE 1: Steel fiber concrete mixing.

TABle 1: The mix design of steel fiber concrete $\left(\mathrm{kg} / \mathrm{m}^{3}\right)$.

\begin{tabular}{lccccc}
\hline $\begin{array}{l}\text { Specimen type } \\
(\%)\end{array}$ & $\begin{array}{c}\text { Coarse } \\
\text { aggregate }\end{array}$ & Sand & Cement & Water & $\begin{array}{c}\text { Steel } \\
\text { fiber }\end{array}$ \\
\hline 0 & 1169 & 635 & 387 & 209 & 0 \\
1 & 1169 & 635 & 387 & 209 & 78.5 \\
2 & 1169 & 635 & 387 & 209 & 157 \\
\hline
\end{tabular}

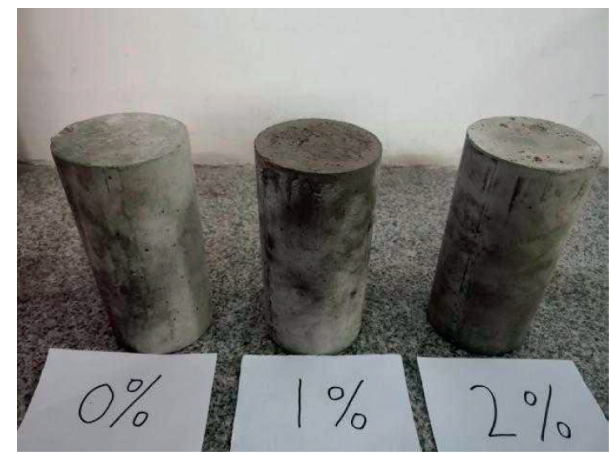

FIGURE 2: SFRC concrete cylinders.

exposure was 28 days. Figure 4 shows that the cylinders were completely immersed into the chemical solutions, and the lid was used to seal at the top of the box to prevent water evaporation, as shown in Figure 4.

An electronic balance weighed the samples after 25, 50, 75 , and 100 freeze-thaw cycles. The balance has an accuracy of $0.1 \mathrm{~g}$. Similarly, the samples soaked in chemical solution were weighed after $7,14,21$, and 28 days in a storage box. Figure 5 shows a typical specimen soaked in water for seven days.

The $\mathrm{pH}$ value of the water tank in the freeze-thaw tester was monitored after every 25 freeze-thaw cycles, as shown in Figure 6(a). Similarly, the $\mathrm{pH}$ value of the corrosion solution in the storage box was measured every 7 days. Figure 6(b) shows the typical $\mathrm{pH}$ measuring of the $\mathrm{NaCl}$ solution.

An electron microscope was used (Figure 7) to observe the microstructure and the specimen surface (position 1), cross section edge (position 2), and cross section center (position 3).

According to the "Standard for Test Methods of Mechanical Properties of Ordinary Concrete" GB/T 50081-2019)[43], the bearing capacity under axial compression was tested (Figure 8). All specimens were

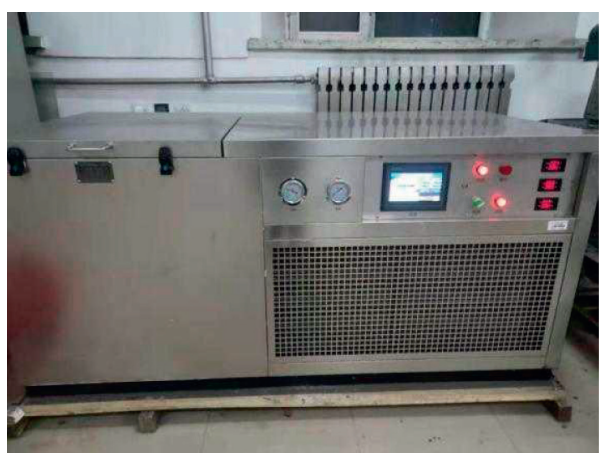

FiguRE 3: KDR-V5 concrete quick freeze-thaw tester.

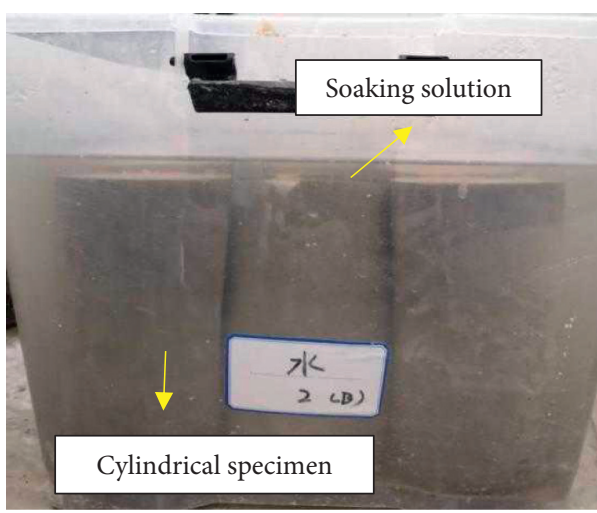

FIgURE 4: Test specimens immersed in storage box.

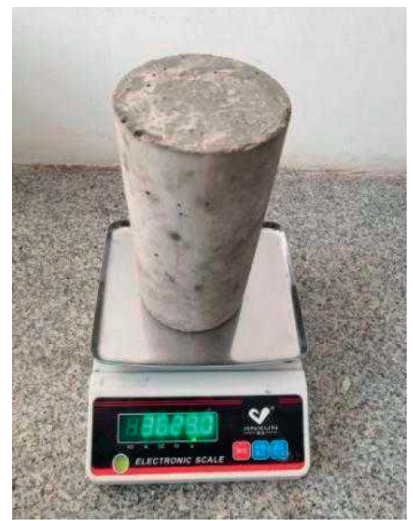

Figure 5: Measuring the mass of the specimens.

continuously and uniformly loaded until failure when subjected to freeze-thaw cycles and chemical immersion, and the loading speed was $0.5 \mathrm{MPa} / \mathrm{s}$.

\section{Results and Discussion}

3.1. Loss of Specimen Mass and Change of $p H$ Value. The quality changes of samples were monitored under the effect of freeze-thaw cycles. In this experiment, the mass after 25, 50,75 , and 100 freezing-thawing cycles was measured, and the mass loss rate was calculated, as shown in Figure 9. The results show that steel fiber's volume content and freezingthawing time influence the mass-loss rate. The higher the 


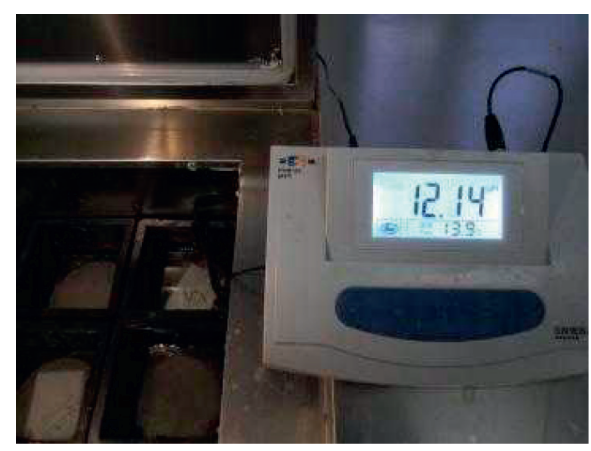

(a)

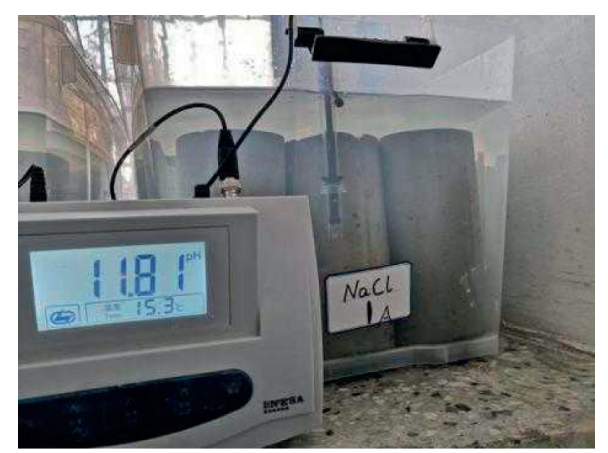

(b)

Figure 6: Measuring the PH. (a) Freeze-thaw cycle environment. (b) Solution immersion environment.

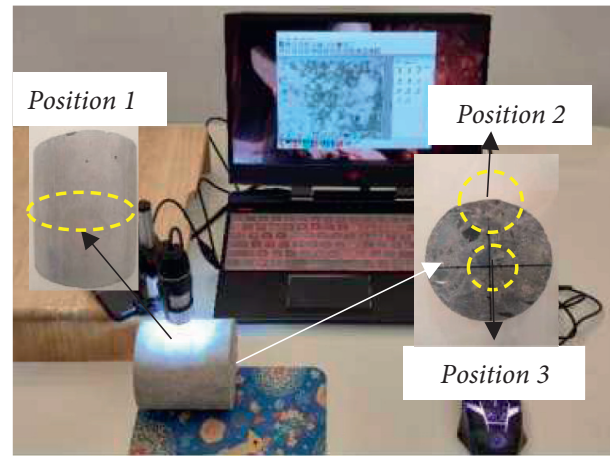

Figure 7: Microscopic observation.

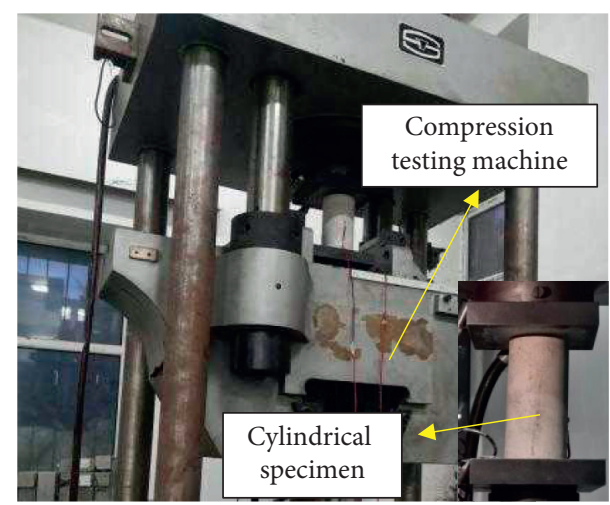

Figure 8: Axial compression test.

steel fiber content, the lower the mass loss rate. The more the time of freezing and thawing, the more pronounced the influence of SFRC quality loss. The mass loss of the sample with the content of $0 \%$ is twice that of the sample with $2 \%$ when the freezing-thawing cycles are close to 100 times, indicating that steel fiber can effectively inhibit the quality loss of concrete caused by freezing-thawing. In the first 25 freezing-thawing cycles, the mass of the specimen has a tendency to increase, which can be interpreted as the water absorption mass of the specimen is more significant than the surface mass loss. However, the quality decreases after 25 times, indicating that the freeze-thaw cycle leads to the quality loss of samples. It can be seen that the mass loss is positively correlated with the number of freezing-thawing

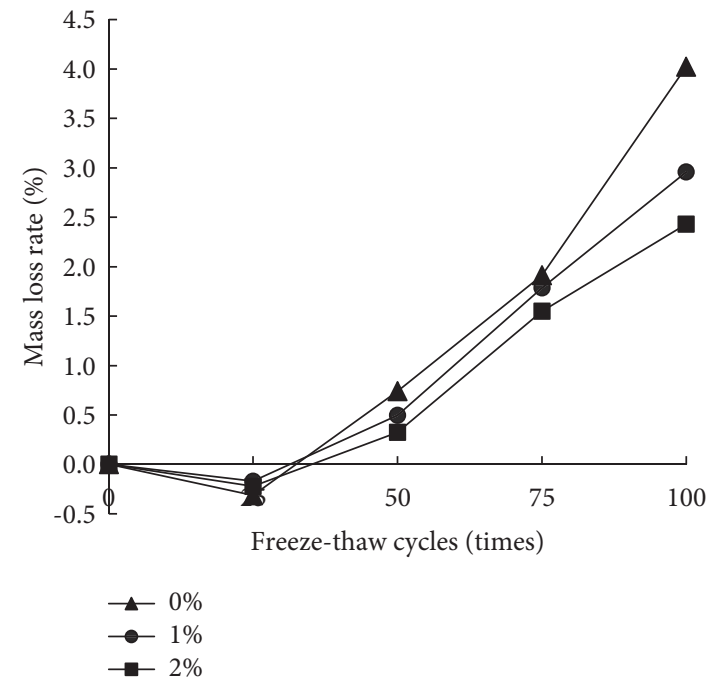

Figure 9: Mass loss rate curve of the freeze-thaw cycle.

cycles, which may be caused by the spalling of the damaged surface of concrete specimens.

The mass of the specimen was measured after immersion in various solutions for 7 days, 14 days, 21 days, and 28 days, as shown in Figure 10. Soaking time and steel fiber content influence the quality trend of the specimen. The specimen mass increases first and then decreases during soaking. The quality variation trend of samples with different steel fiber content was similar, indicating that steel fiber content has little influence on the quality of samples. The more the steel fiber content used, the more mass loss improvement is obtained. However, the steel fiber content slightly affects the small value $(<10 \mathrm{~g})$. The quality of samples measured in $\mathrm{H}_{2} \mathrm{SO}_{4}$ solution every 7 days is shown in Figure $10(\mathrm{~d})$, decreasing continuously. The quality loss of steel fiber reinforced concrete was less than that of ordinary concrete, and with the increase of time, the quality loss became more apparent. The quality loss of plain concrete was twice that of fiber concrete, so the addition of steel fiber can effectively weaken the quality loss of concrete caused by sulfuric acid. The mass of the sample soaked in $\mathrm{NaOH}$ solution is shown in Figure 10(e). After soaking for 14 days, the mass of plain concrete specimens decreased, while fiber concrete 

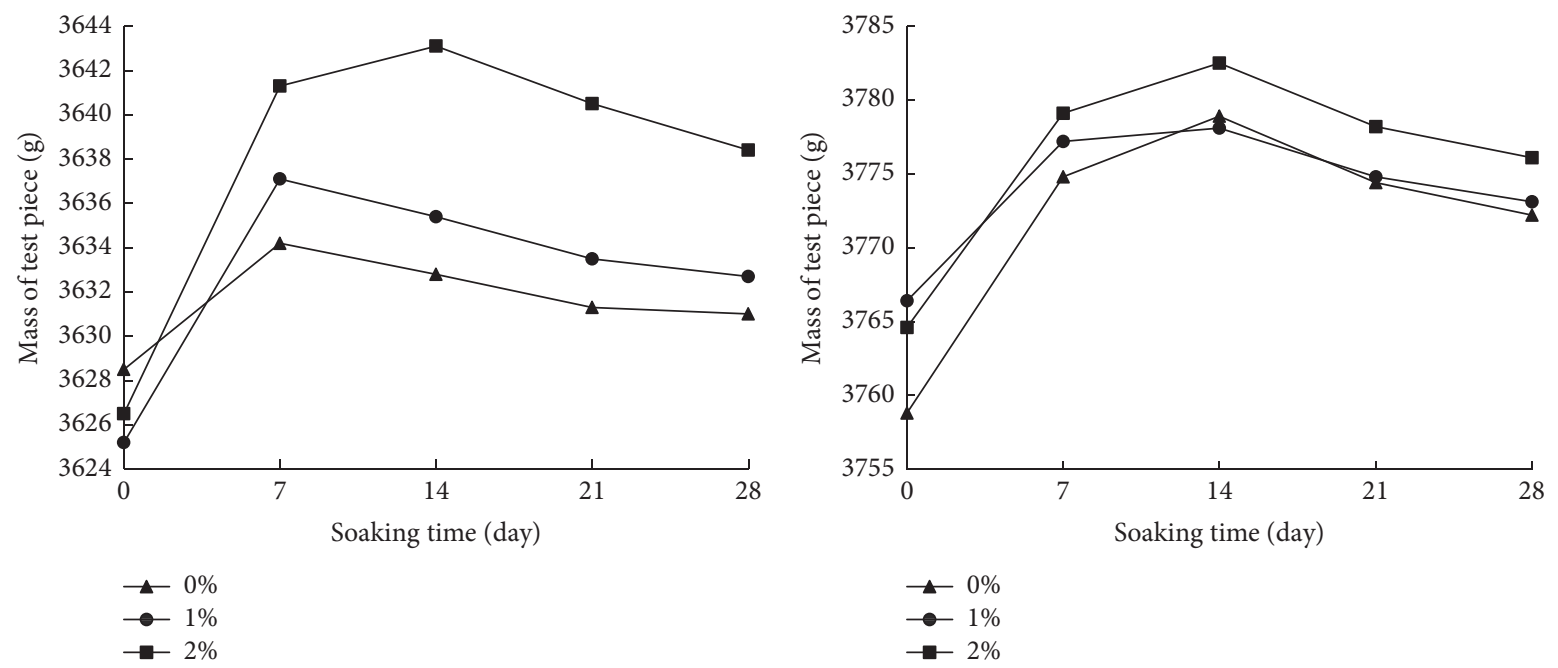

(a)
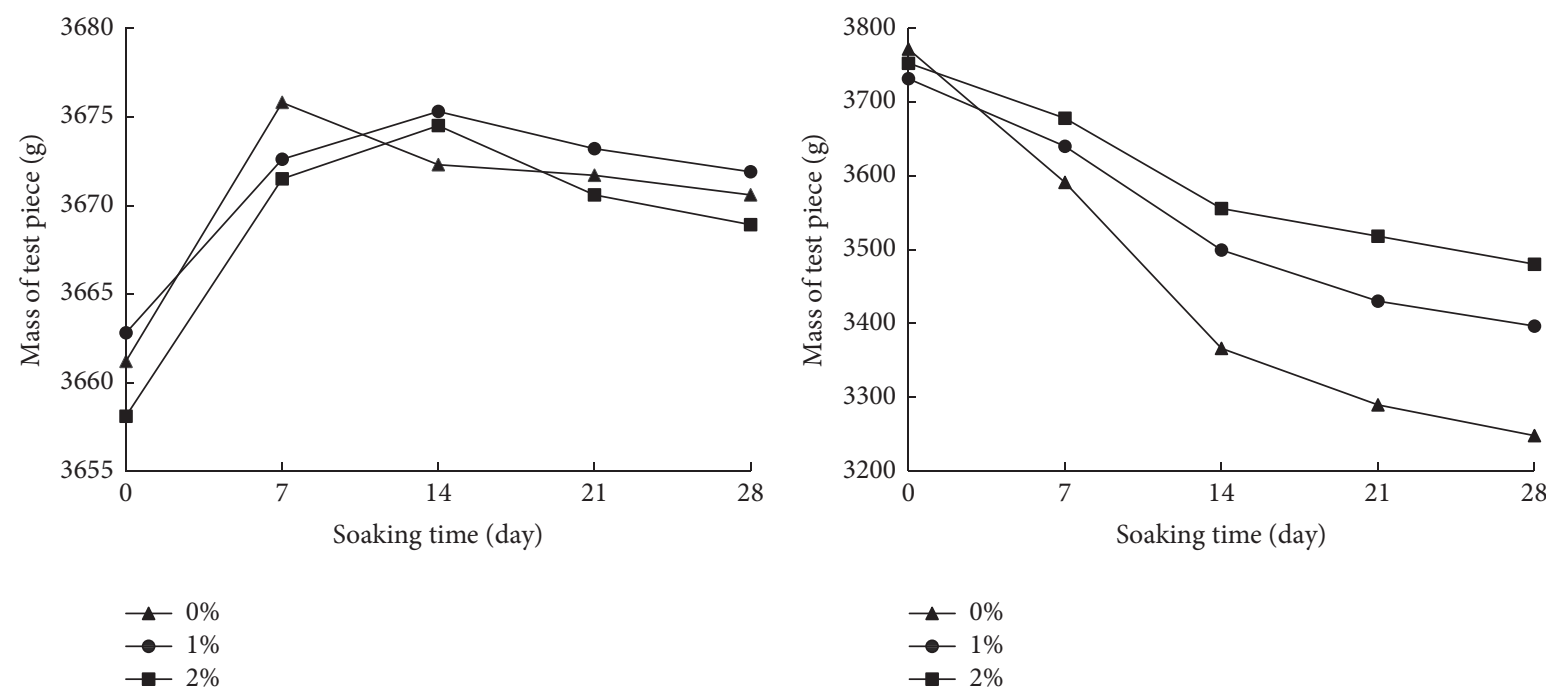

(c)

(d)

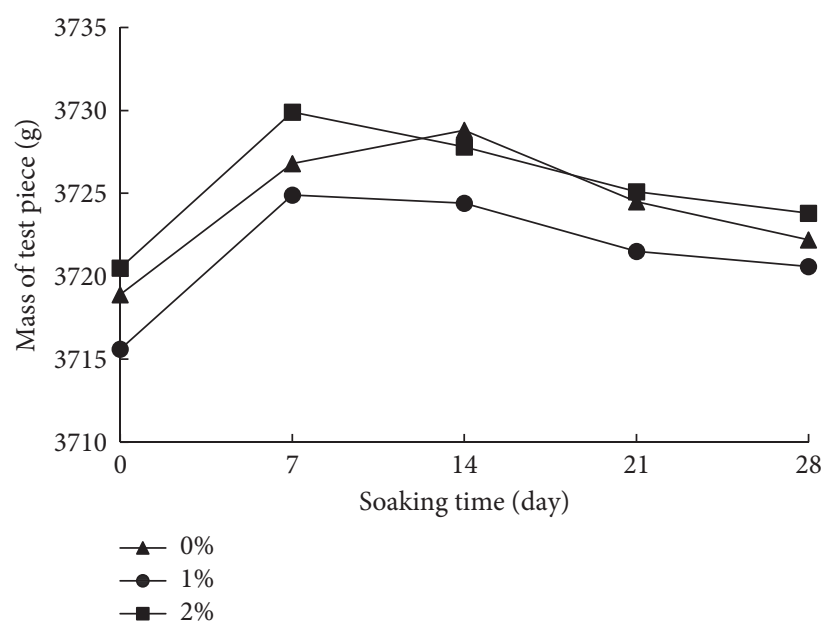

(e)

FIGURE 10: Mass change of specimen in various solutions. (a) Mass change of specimen soaked in water. (b) Mass change of specimen soaked in $\mathrm{NaCl}$ solution. (c) Mass change of specimen soaked in $\mathrm{Na}_{2} \mathrm{SO}_{4}$ solution. (d) Mass change of specimen soaked in sulfuric $\mathrm{H}_{2} \mathrm{SO}_{4}$ solution. (e) Mass change of specimen soaked in $\mathrm{NaOH}$ solution. 
decreased on the seventh day. The quality change of steel fiber-reinforced concrete specimens was similar to that of plain concrete. The content of steel fiber has little effect on the quality change of samples soaked in $\mathrm{NaOH}$ because of the small change $(<10 \mathrm{~g})$.

A comparison of the mass loss of specimens with different steel fiber content after soaking in different environments for 28 days and after freeze-thaw cycles 100 times is shown in Figure 11. The freeze-thaw cycle and $\mathrm{H}_{2} \mathrm{SO}_{4}$ immersion environment have caused an apparent quality loss, while other environments have a relatively weak influence on specimens' quality loss. Therefore, it is concluded that the freeze-thaw cycle and $\mathrm{H}_{2} \mathrm{SO}_{4}$ solution are the immediate environments of concrete structure destruction through the comparison of mass loss. Furthermore, the mass loss decreases after adding steel fiber, and the more steel fiber is added, the smaller the mass loss is.

The $\mathrm{pH}$ value of the freezing-thawing solution is measured after every 25 freezing-thawing cycles, as shown in Figure 12. The $\mathrm{pH}$ value increases continuously, and the growth rate trend decreases from large to small. The concrete itself is alkaline, and the water is neutral. The $\mathrm{pH}$ of the immersion solution slowly rises at the beginning of freezingthawing, which is caused by the concrete surface being exposed to water. With the increase of freeze-thaw cycles, cracks appear in concrete, and more concrete particles come into contact with water, resulting in an accelerated increase in $\mathrm{pH}$ value. After that, most of the water contacts the concrete inside and outside, and the reaction between water and concrete alkaline substances is weakened, resulting in slow $\mathrm{pH}$ change.

The chemical corrosion test of concrete specimens with three contents was carried out for 28 days. The variation of $\mathrm{pH}$ value is shown in Figures 13(a) and 13(b). As the test piece itself is alkaline, acid-base neutralization occurs in sulfuric acid solution, and the $\mathrm{pH}$ value increases significantly, but the $\mathrm{pH}$ value in other solutions does not change significantly.

\subsection{Analysis of Mechanical Deterioration Performance of} SFRC. A cube compressive test was carried out on cube specimens after standard curing for 28 days. Figure 14 shows the specimen shape after the failure of the steel fiber-reinforced concrete cube compression test, and Table 2 shows the cube compressive strength of concrete with three steel fiber contents.

It can be concluded that the SFRC compressive strength has a positive effect with an increase in steel fiber contents. The steel fiber content is $1 \%$ and $2 \%$, and the compressive strength increases by $11.4 \%$ and $30.6 \%$, respectively. The addition of steel fiber can restrain the concrete transverse deformation, which is beneficial for improving the concrete's compressive strength. On the other hand, steel fiber promotes the development of a harmful interface between concrete and steel fiber. The interface is suddenly destroyed when the compressive load reaches a specific value.

Cylindrical concrete specimens with a steel fiber content of $0 \%, 1 \%$, and $2 \%$ were subjected to the axial compression

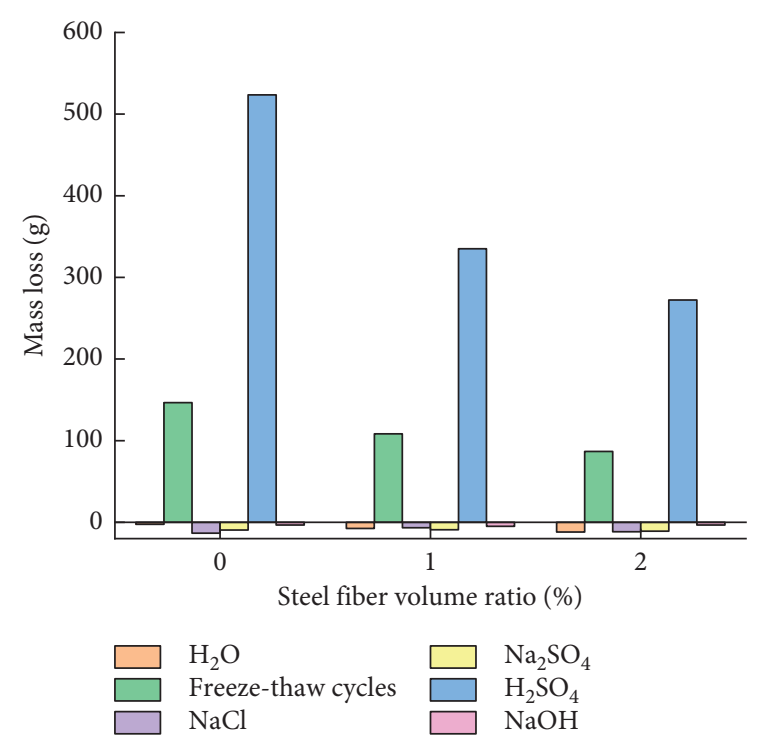

FIGURE 11: Comparison of mass loss after environmental erosion.

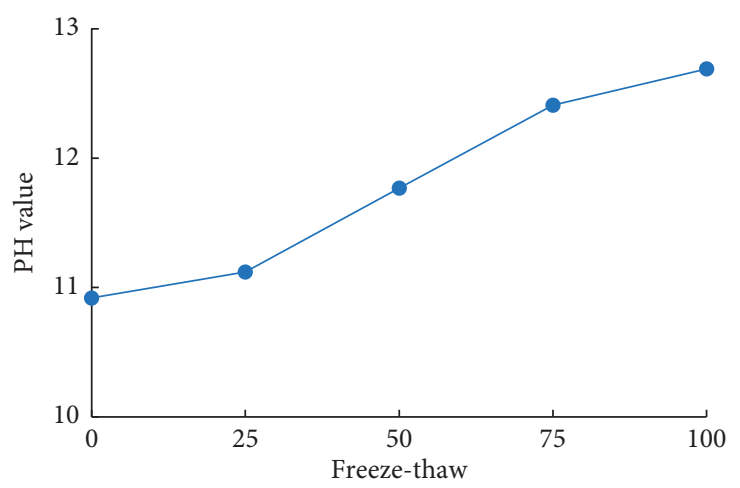

Figure 12: Changes of $\mathrm{pH}$ value in freeze-thaw environment.

test after 100 freeze-thaw cycles and 28 days in different solutions. A schematic diagram of the axial compression test of specimens with other volume content of steel fiber is shown in Figure 15. The more steel fiber content, the less noticeable the surface failure of the specimen, and the better the integrity of the specimen after failure, the less the surface mortar falls off.

The axial compression test results of cylindrical specimens are shown in Figure 16. It is observed that the intensity changes are different under different erosion environments. The more steel fiber is added, the higher the strength of the specimen. However, with the decrease of erosion failure strength, the strength of the specimen with the same fiber volume content is different in different erosion environments. Adding steel fiber can effectively improve its axial compression strength compared to axial compression data before and after. The improvement degree varies significantly in different environments, with the maximum improvement degree under freeze-thaw cycle and the minimum improvement degree strength under sodium sulfate environment.

The higher the steel fiber content, the greater the compressive strength of SFRC obtained in different 


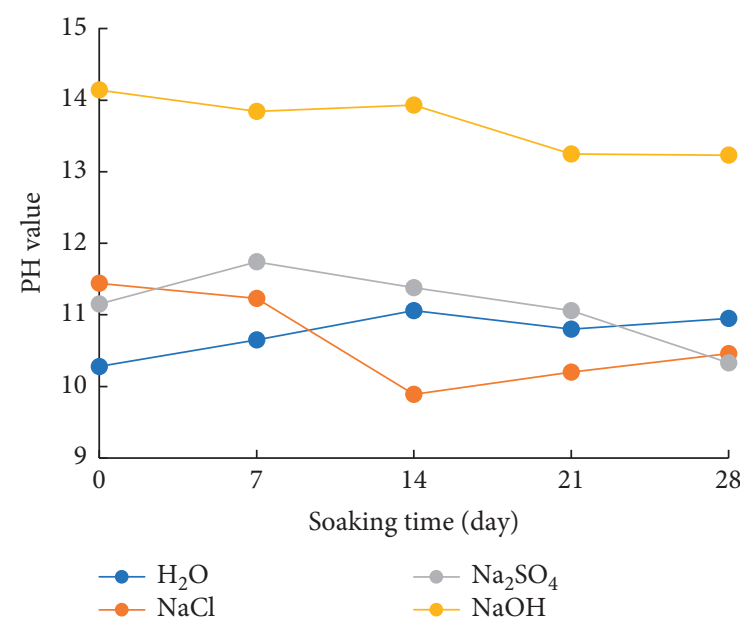

(a)

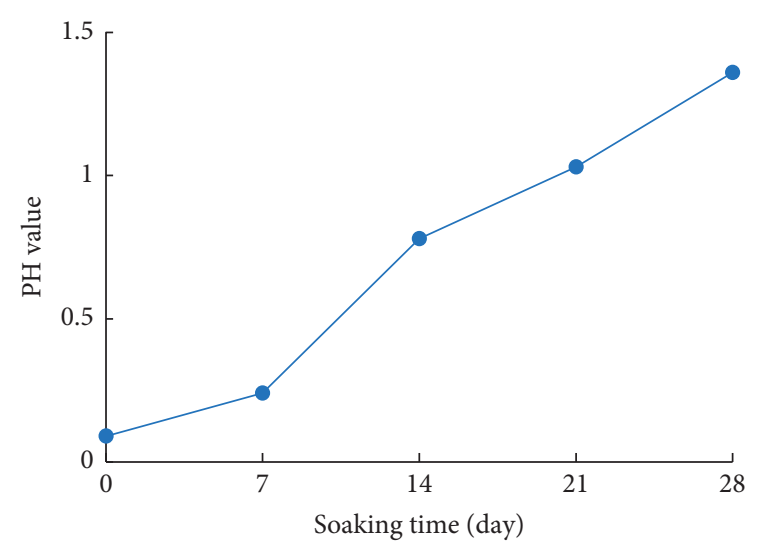

(b)

FiguRE 13: Erosion environment $\mathrm{pH}$ change. (a) $\mathrm{pH}$ change. (b) $\mathrm{pH}$ change of sulfuric acid solution.

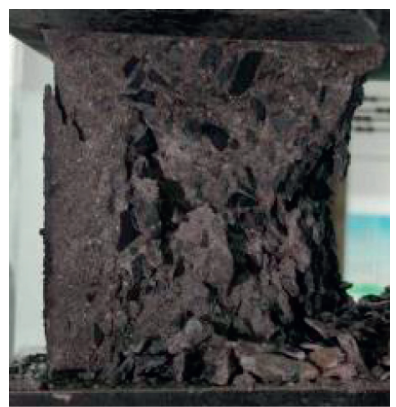

(a)

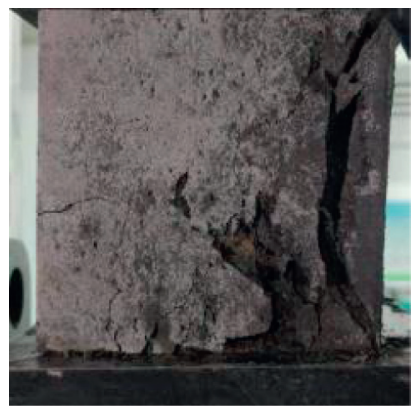

(b)

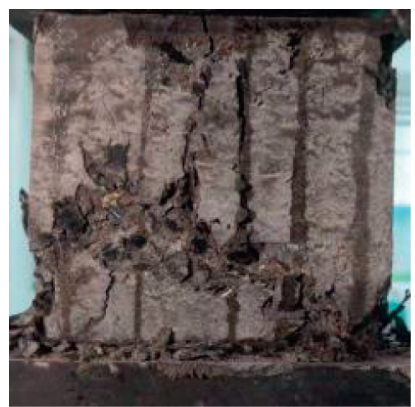

(c)

Figure 14: Concrete cubic compressive test. (a) $0 \%$. (b) $1 \%$. (c) $2 \%$.

TABle 2: Compressive strength of concrete cube.

\begin{tabular}{lccc}
\hline Type (steel fiber content) & $0 \%$ & $1 \%$ & $2 \%$ \\
\hline Compressive strength & 30.7 & 34.2 & 40.1 \\
\hline
\end{tabular}

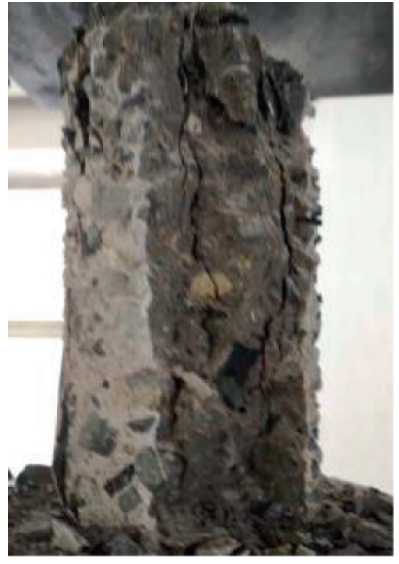

(a)

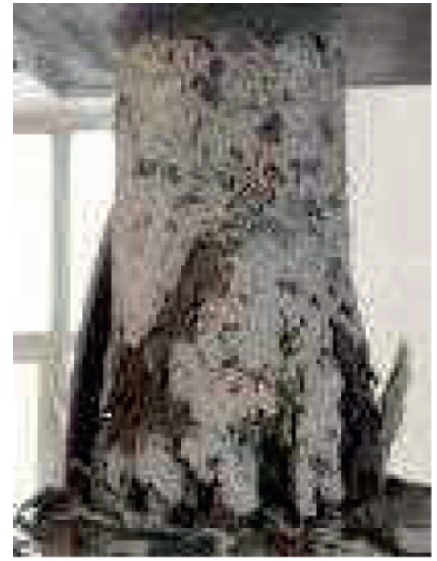

(b)

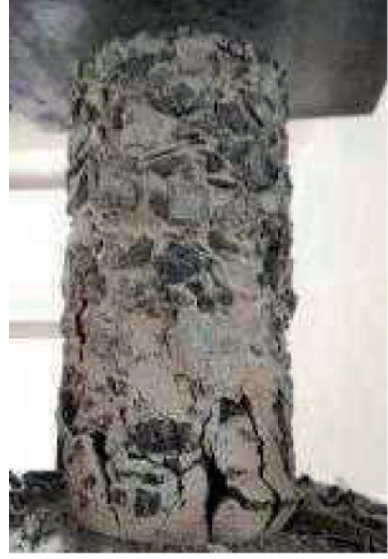

(c)

Figure 15: Axial compression test. (a) $0 \%$. (b) $1 \%$. (c) $2 \%$. 

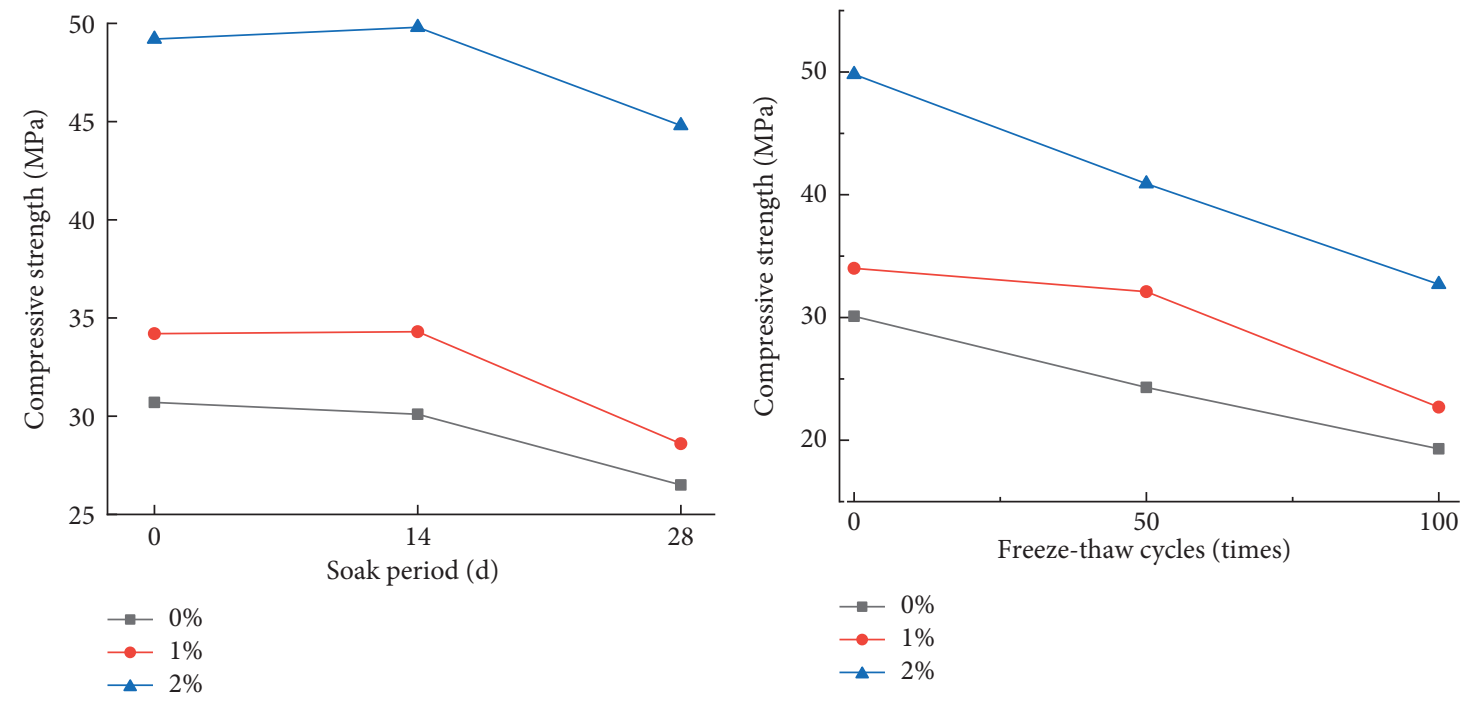

(a)
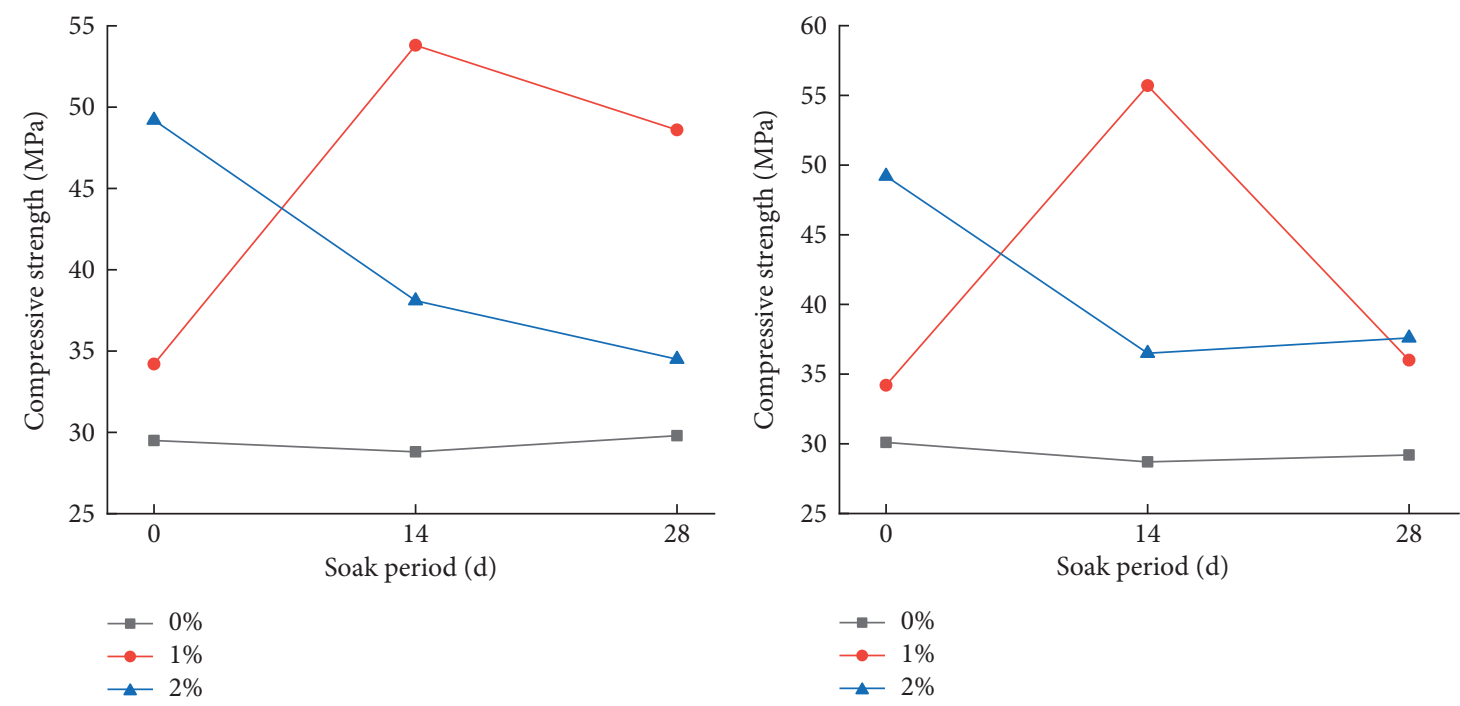

(c)
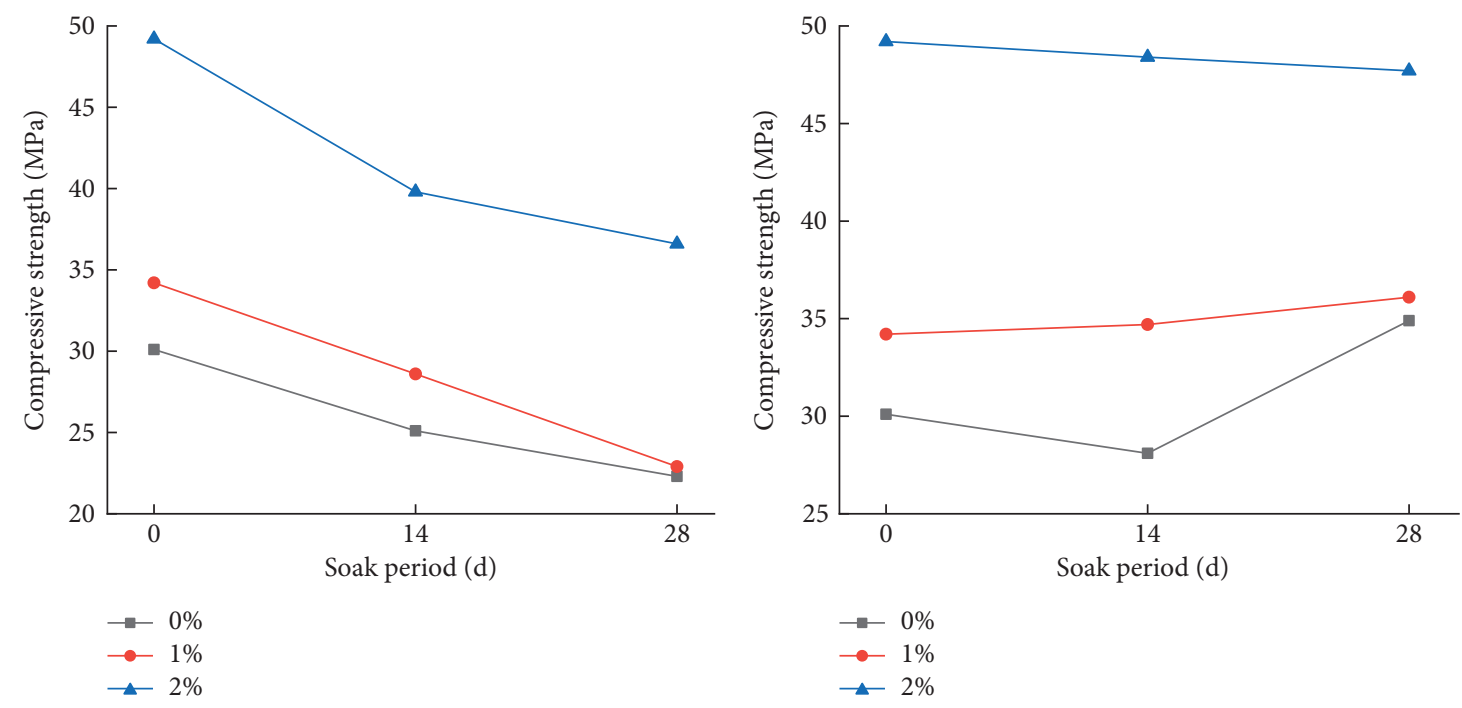

(e)

(f)

Figure 16: Axial compressive strength of specimen soaked in solution. (a) Specimens soaked in water. (b) Freeze-thaw specimen. (c) Specimens soaked in $\mathrm{NaCl}$ solution. (d) Specimens soaked in $\mathrm{Na}_{2} \mathrm{SO}_{4}$ solution. (e) Specimens soaked in $\mathrm{H}_{2} \mathrm{SO}_{4}$ solution. (f) Specimens soaked in $\mathrm{NaOH}$ solution. 
environments. It can effectively prevent transverse deformation and show the best reinforcement effect when the fiber is vertically oriented. The axial compressive strength of the specimen shows a downward trend in the process of erosion, indicating the continuous deterioration of concrete in various adverse environments. Figure 17 shows the capacity growth rate of steel fiber-reinforced concrete relative to ordinary concrete under different erosion environments. It can be concluded that the steel fiber can effectively prevent concrete corrosion under chemical attack.

According to the test data, the loss rate of compressive strength of specimens with three contents after six kinds of environmental erosion was calculated in Figure 18. The strength loss rate is either positive or negative. The positive number indicates that the strength decreases, while the negative number means that the strength increases. It can be concluded that the optimum steel fiber content is different under various erosion environments. The different erosion environments have various effects on the axial compressive strength of concrete. Through the calculation of compressive strength loss value, it can be concluded that the damage degree of the unfavorable environment to concrete is as follows: freeze-thaw cycle $>$ dilute sulfuric acid $>$ sodium chloride $>$ water $>$ sodium sulfate $>$ sodium hydroxide.

3.3. Microscopic Observation Analysis. After 100 freeze-thaw cycles, the surface (position 1) and cross section (position 2, position 3) of the specimens with three fiber contents were observed microscopically, and 500 times magnification factors were used to observe the variation trend. Figure 19 shows specimen position 1 with a steel fiber content of $0 \%$, $1 \%$, and $2 \%$ when subjected to 100 freeze-thaw cycles. There are many small cracks on the surface of plain concrete specimens no matter the fiber content, but the crack width tends to decrease.

Similarly, the cross-sectional of position 2 observation result is shown in Figure 20. The cracks appear in all-fiber content concrete specimens. With the increase of fiber content, the crack length obviously decreased, which shows that adding steel fiber can partially restrain the crack development when subjected to a freeze-thaw cycle.

Figure 21 shows the cross section position of three microscopically observation results. A small number of cracks appeared in plain concrete specimens after 100 freeze-thaw cycles, micro-cracks appeared in fiber concrete with $1 \%$ content after 100 freeze-thaw cycles, and no cracks appeared in fiber concrete with $2 \%$ content. It can be observed that steel fiber can inhibit cracks' development in concrete specimens.

Microscopic comparison between position 2 and position 3 shows that the crack width and length at position 2 are more significant than position 3 . Therefore, it can be explained that the crack developed from the surface to the inside, and adding steel fiber can reduce the damage caused by freeze-thaw cycles. After soaking in water for 28 days, the microscopic observation at position 1 of specimens with a steel fiber content of $0 \%, 1 \%$, and $2 \%$ was shown in Figure 22. The surface of the samples with different fiber content had no apparent difference.

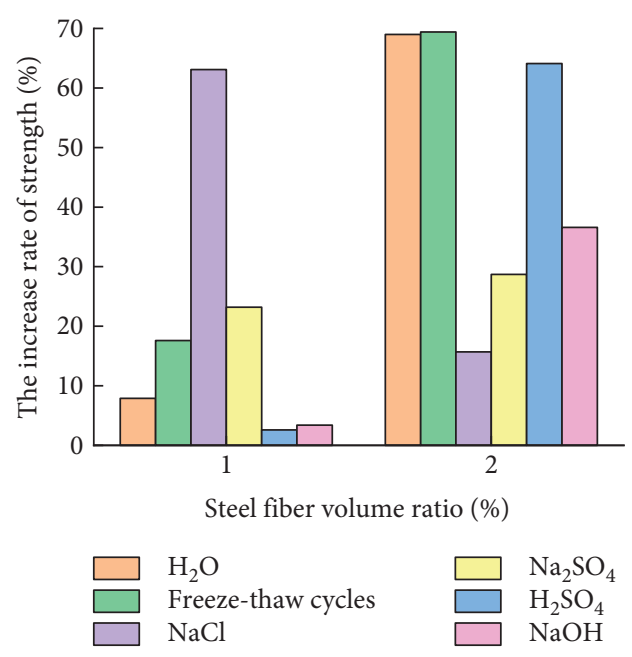

FIGURE 17: The increase rate of strength (\%).

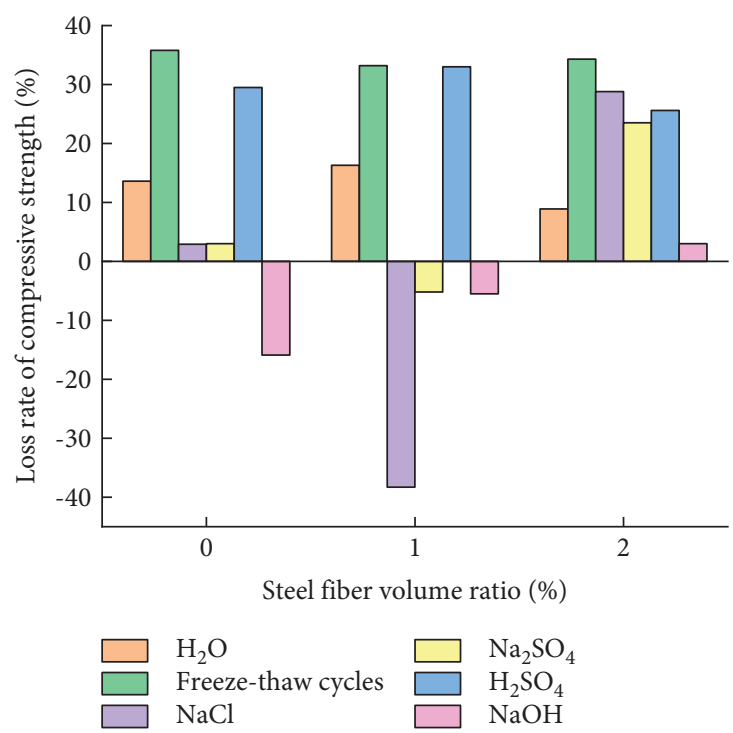

Figure 18: Loss rate of compressive strength (\%).

Similarly, microscopic observation was carried out on position 2 and position 3, and the specimens with three kinds of contents after soaking in water for 28 days showed no change. Unfortunately, only the micrograph of position 2 was displayed due to space limitations, as shown in Figure 23. It can be seen that steel fiber does not affect the crack variation in water.

After soaking in $\mathrm{NaCl}$ solution for 28 days, the specimen with a steel fiber content of $0 \%, 1 \%$, and $2 \%$ was observed, as shown in Figure 24. The specimen with different fiber content had similar cracks developed on the surface after soaking for 28 days, and the fiber content had no significant damages.

Similarly, Figure 25 shows the cross section of position 2 crack development. Plain concrete $(0 \%)$ specimens have cracks after soaking for 28 days, and others have no cracks. It can be seen that adding steel fiber can inhibit the cracks of specimens soaked in $\mathrm{NaCl}$ solution. 


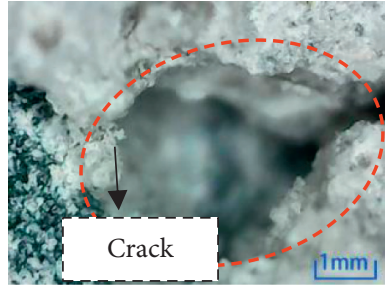

(a)

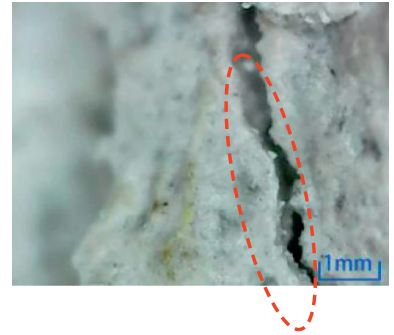

(b)

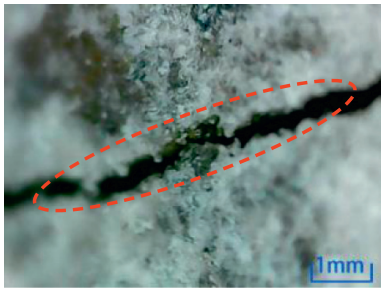

(c)

FIgURe 19: Microscopic observation of position 1 in 100 times freeze-thaw cycles. (a) $0 \%$. (b) $1 \%$. (c) $2 \%$.

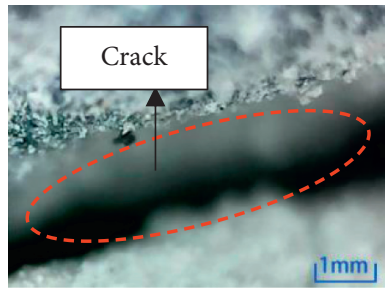

(a)

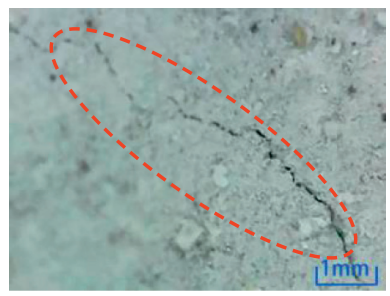

(b)

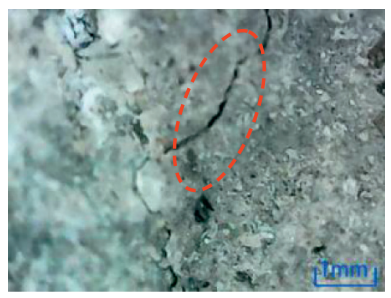

(c)

Figure 20: Microscopic observation of position 2 in 100 times freeze-thaw cycles. (a) $0 \%$. (b) $1 \%$. (c) $2 \%$.

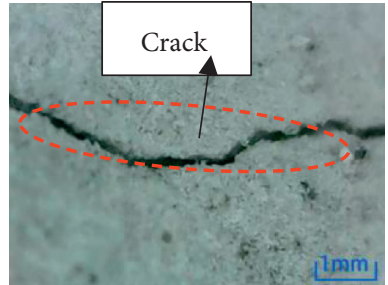

(a)

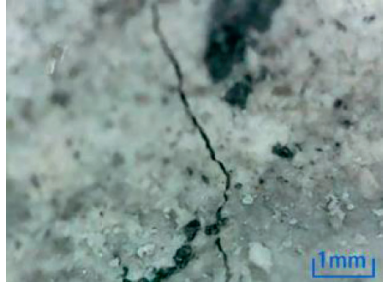

(b)

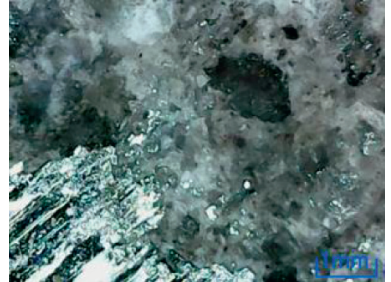

(c)

Figure 21: Microscopic observation of position 3 in 100 times freeze-thaw cycles. (a) $0 \%$. (b) 1\%. (c) $2 \%$.

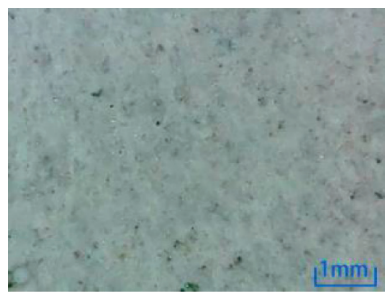

(a)

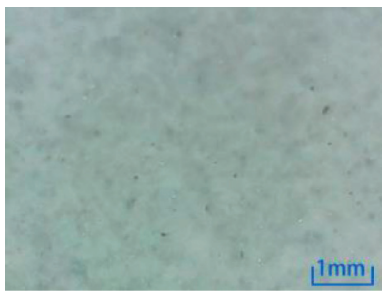

(b)

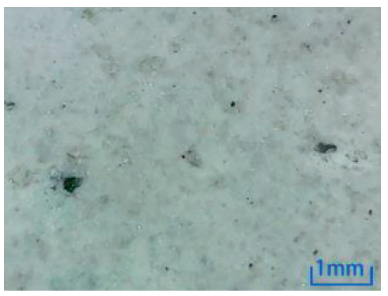

(c)

FIGURE 22: Microscopic observation of water immersion specimen at position 1 . (a) $0 \%$. (b) $1 \%$. (c) $2 \%$.

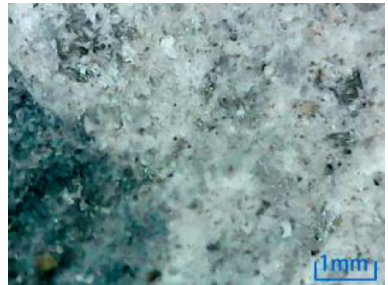

(a)

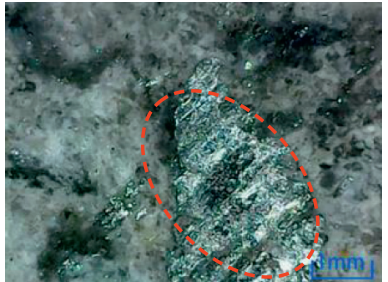

(b)

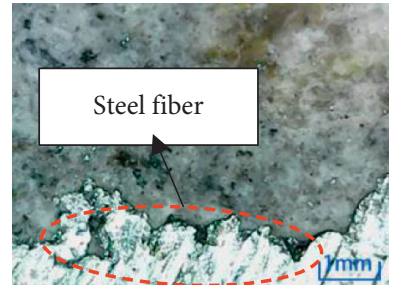

(c)

Figure 23: Microscopic observation of water immersion specimen at position 2 . (a) $0 \%$. (b) $1 \%$. (c) $2 \%$. 


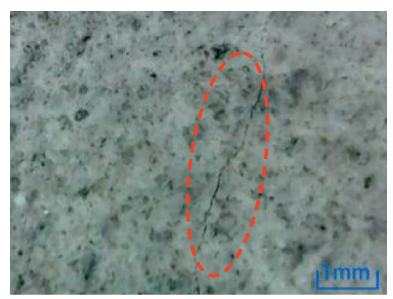

(a)

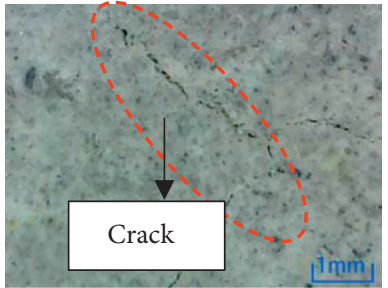

(b)

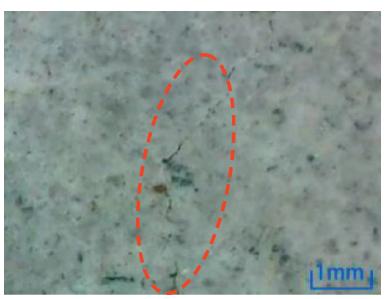

(c)

Figure 24: Microscopic observation of specimen soaked in $\mathrm{NaCl}$ solution at position 1 . (a) $0 \%$. (b) $1 \%$. (c) $2 \%$.

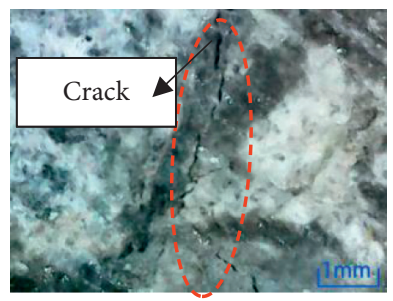

(a)

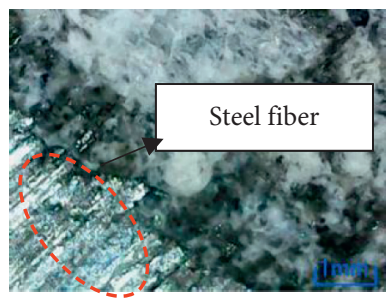

(b)

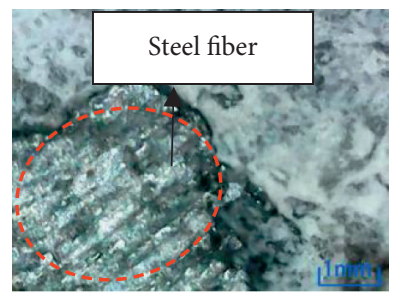

(c)

Figure 25: Microscopic observation of specimen soaked in $\mathrm{NaCl}$ solution at position 2. (a) $0 \%$. (b) $1 \%$. (c) $2 \%$.

No cracks were found in all specimens with three fiber dosages at position 3 after soaking for 28 days. Thus, compared with position 2 and position 3 , the $\mathrm{NaCl}$ solution penetrates the sample from outside to inside, and steel fiber can effectively inhibit corrosion. The samples with different contents $(0 \%, 1 \%$, and $2 \%)$ were soaked in $\mathrm{Na}_{2} \mathrm{SO}_{4}$ solution for 28 days, and the steel fiber content did not affect the cracks of the samples soaked in $\mathrm{Na}_{2} \mathrm{SO}_{4}$ solution in position 1, as shown in Figure 26.

After soaking in $\mathrm{Na}_{2} \mathrm{SO}_{4}$ solution for 28 days, the transverse position 2 and position 3 of various samples were observed, as shown in Figure 27. There was no difference in the internal structure of the specimens with three fiber contents.

The position 1 cracks appear in all samples with different fiber contents after soaking in $\mathrm{H}_{2} \mathrm{SO}_{4}$ for 28 days, as shown in Figure 28. More cracks appear in samples with an increase in steel fiber content. It can be seen that steel fiber accelerates the surface cracks when subjected to $\mathrm{H}_{2} \mathrm{SO}_{4}$ exposure.

After soaking in $\mathrm{H}_{2} \mathrm{SO}_{4}$ solution for 28 days, the samples at position 2 and position 3 have no cracks observed, as shown in Figure 29.

Figure 30 shows position 1 of the specimens' microscopic observation after soaking in $\mathrm{NaOH}$ solution for 28 days. Again, the specimens with steel fiber appeared to have larger cracks, indicating that the increased steel fiber content accelerated cracks with prolonged soaking time.

After soaking in $\mathrm{NaOH}$ solution for 28 days, there was no noticeable difference of the samples with three different fiber contents at position 2 and position 3 . It can be seen that the steel fiber content does not affect the change of the sample's internal structure, as shown in Figure 31.

According to the observation results, the freeze-thaw cycle and chemical erosion environment have adverse effects on steel fiber concrete with different content and promote the occurrence and development of cracks. The steel fiber provides remarkable shear capacity for developing cracks, which leads to SFRC showing a pseudo-ductility response. It also increased residual tensile strength and enhanced energy dissipation capacity compared with the brittle behavior of ordinary concrete. The addition of steel fiber can restrain some cracks to a certain extent, but the effectiveness gap is evident in different corrosive environments, so it is necessary to determine the optimal content of steel fiber in different corrosive environments.

It can be found that there were no cracks on the surface of soaked concrete immersed in water, comparing the microscopic observation results of the position under six environments, and cracks appeared in varying degrees in the environment of the freeze-thaw cycle, sodium chloride, sodium sulfate, dilute sulfuric acid, and sodium hydroxide. The addition of steel fiber can inhibit the damage of the freeze-thaw cycle to concrete, but it has no effect on concrete in the environment of sodium chloride and sodium sulfate. On the other hand, it harms concrete in the environment of dilute sulfuric acid and sodium hydroxide but promotes the generation of surface cracks. Therefore, by comparing the size and length of cracks in specimens under adverse erosion environments, the order of crack development is: dilute sulfuric acid $>$ freeze-thaw cycle $>$ sodium hydroxide $>$ sodium sulfate $>$ sodium chloride $>$ water.

Compared with the microscopic observations at position 2 and position 3 in all environments, it is found that the concrete after immersion has no cracks, the concrete under freeze-thaw cycle has cracks, and the cracks are reduced after adding steel fiber. There are cracks in plain concrete of specimens soaked in sodium chloride environment, but there are no cracks in steel fiber concrete, which fully proves the anti-crack effect of steel fiber. Therefore, it is concluded that the damage degree of the adverse environment to concrete is: freeze-thaw cycle $>$ sodium chloride $>$ others. 


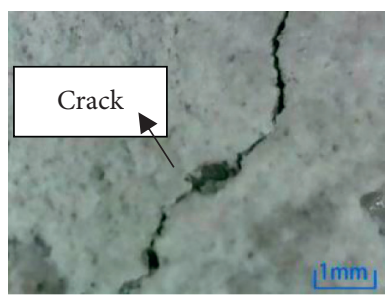

(a)

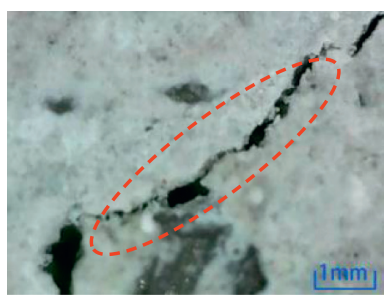

(b)

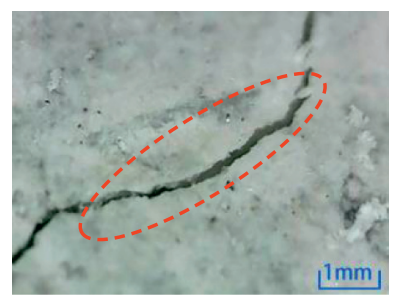

(c)

FIGURE 26: Microscopic observation of specimen soaked in $\mathrm{Na}_{2} \mathrm{SO}_{4}$ solution at position 1. (a) $0 \%$. (b) $1 \%$. (c) $2 \%$.

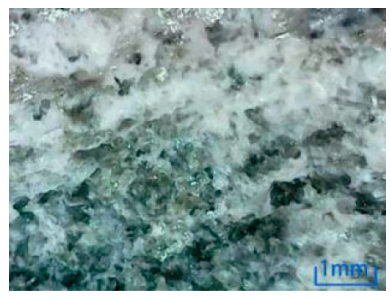

(a)

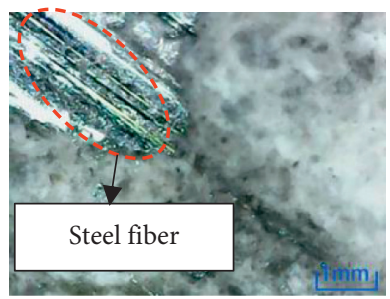

(b)

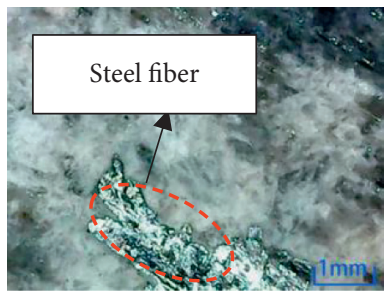

(c)

FIGURE 27: Microscopic observation of specimen soaked in $\mathrm{Na}_{2} \mathrm{SO}_{4}$ solution at position 2. (a) $0 \%$. (b) $1 \%$. (c) $2 \%$.

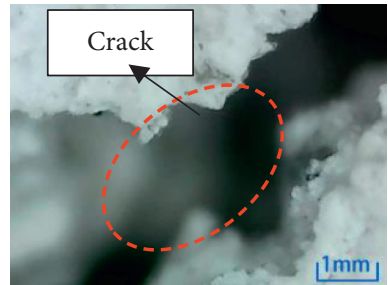

(a)

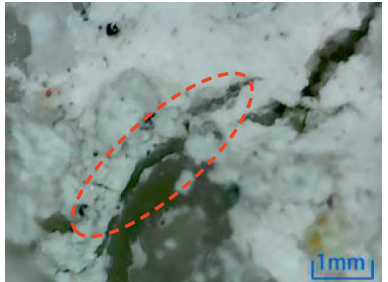

(b)

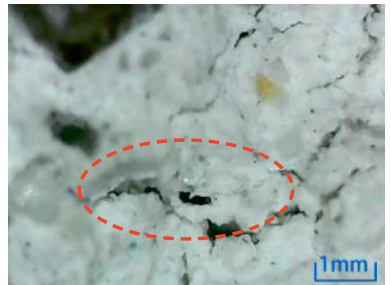

(c)

Figure 28: Microscopic observation of specimen soaked in $\mathrm{H}_{2} \mathrm{SO}_{4}$ solution at position 1. (a) $0 \%$. (b) $1 \%$. (c) $2 \%$.

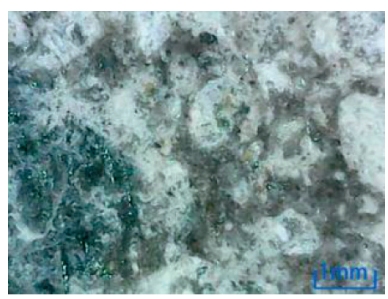

(a)

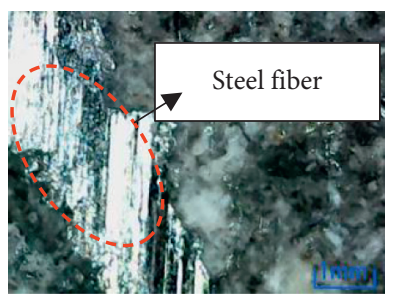

(b)

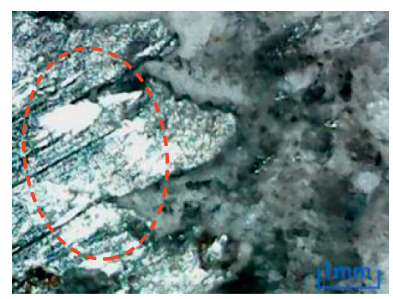

(c)

FIgURE 29: Microscopic observation of specimen soaked in $\mathrm{H}_{2} \mathrm{SO}_{4}$ solution at position 2. (a) $0 \%$. (b) $1 \%$. (c) $2 \%$.

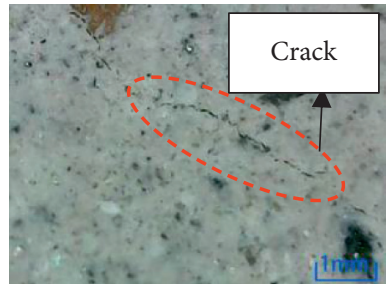

(a)

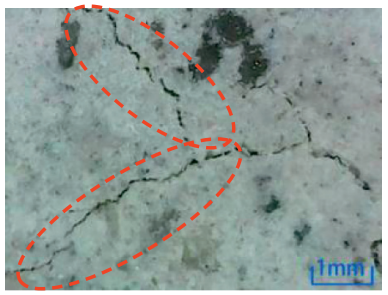

(b)

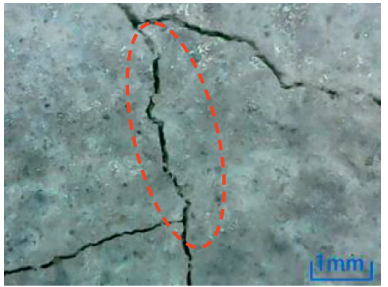

(c)

FIgURE 30: Microscopic observation of specimen soaked in $\mathrm{NaOH}$ solution at position 1 . (a) $0 \%$. (b) $1 \%$. (c) $2 \%$. 


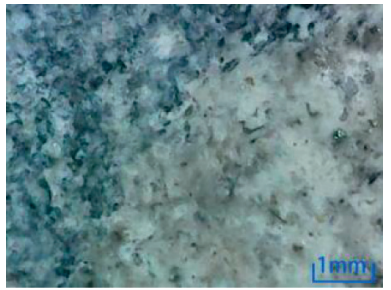

(a)

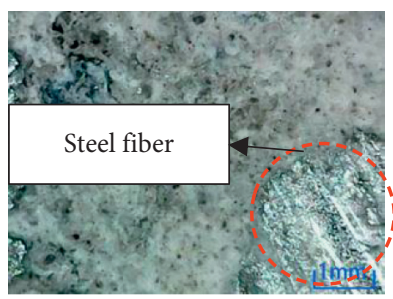

(b)

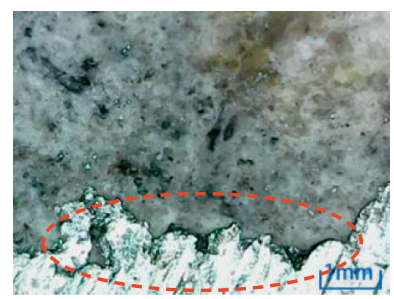

(c)

Figure 31: Microscopic observation of specimen soaked in $\mathrm{NaOH}$ solution at position 2. (a) $0 \%$. (b) $1 \%$. (c) $2 \%$.

TABLE 3: Results of concrete strength analysis.

\begin{tabular}{|c|c|c|c|}
\hline Environmental erosion conditions & Regression equation & $R^{2}$ & RSS \\
\hline $\mathrm{H}_{2} \mathrm{O}$ & $f_{c}=7.05 x^{2}-4.95 x+26.5$ & 0.94 & 35.44 \\
\hline Freeze-thaw cycles & $f_{c}=3.3 x^{2}+0.1 x+19.3$ & 0.89 & 35.22 \\
\hline $\mathrm{NaCl}$ & $f_{c}=-16.45 x^{2}+35.25 x+29.8$ & 0.95 & 27.94 \\
\hline $\mathrm{Na}_{2} \mathrm{SO}_{4}$ & $f_{c}=-2.6 x^{2}+9.4 x+29.2$ & 0.80 & 30.52 \\
\hline $\mathrm{H}_{2} \mathrm{SO}_{4}$ & $f_{c}=6.05 x^{2}-4.45 x+21.3$ & 0.88 & 58.06 \\
\hline $\mathrm{NaOH}$ & $f_{c}=5.1 x^{2}-3.9 x+34.9$ & 0.89 & 35.86 \\
\hline
\end{tabular}

SFRC enhances crack resistance in various corrosive environments, and under certain conditions, brittle shear failure can be transformed into ductile bending failure, so steel fiber is a promising nonconventional steel mass reinforcement.

3.4. Numerical Simulation Analysis. After 100 times of freezing, thawing, and soaking for 28 days, the relationship between axial compressive strength and steel fiber content of various cylindrical specimens was numerically simulated and analyzed. The regression analysis results are shown in Table 3.

Concrete with different fiber content has different erosion degrees in different erosion environments. This is because the axial compressive strength of concrete increases after adding steel fiber, and the optimum range of steel fiber in different environments are different, as shown in Table 4.

3.5. Finite Element Analysis. The analysis of test results shows that the freezing-thawing cycle is very harmful to concrete, so fiber concrete freezing-thawing cycle finite element simulation analysis is selected. The existing sizeable finite element software is abundant in temperature field analysis. According to the temperature field analysis of Abaqus, the temperature changes of structural environment in freeze-thaw tests are restored in this paper. The analysis principle of heat conduction in the Abaqus temperature field is heat conduction theory. Due to the existence of a temperature field, functional structures and components under freezing-thawing cycles usually produce temperature stress, including stable temperature stress and transient temperature stress, which adapt to time, and will become essential stresses affecting the durability of structures. Due to the complex internal structure and the changeable temperature field conditions, it is difficult to calculate the temperature
Table 4: Optimum content of steel fiber in different erosion environments.

\begin{tabular}{lc}
\hline Environmental erosion conditions & Optimum volume ratio (\%) \\
\hline $\mathrm{H}_{2} \mathrm{O}$ & 2 \\
Freeze-thaw cycles & 2 \\
$\mathrm{NaCl}$ & 1 \\
$\mathrm{Na}_{2} \mathrm{SO}_{4}$ & 1 \\
$\mathrm{H}_{2} \mathrm{SO}_{4}$ & 2 \\
$\mathrm{NaOH}$ & 2 \\
\hline
\end{tabular}

field accurately in traditional tests, so the finite element method effectively solves the above problems.

The analysis process of heat conduction in Abaqus can be divided into three categories. First, transient heat conduction analysis combined with sequential thermal stress is chosen as the freezing-thawing test simulation analysis method. Second, it is assumed that the concrete structure is a continuous homogeneous and whole elastic structure when calculating the thermal stress of concrete temperature field in finite element software. Third, the elastic reference theory is used to solve the thermal stress in the concrete structure. Finally, the thermodynamic parameters of the model are set in Table 5.

The size of the concrete fiber column model is consistent with the experimental design, and the geometric size and material characteristics of steel fiber are also consistent with the experimental material parameters. The grid-type selects the heat transfer type, the eight-node linear heat transfer hexahedron unit DC3D8, and the steel fiber is the two-node heat transfer connection unit DC1D2. Select the geometric order of the linear element, that is, the first-order element, arrange the nodes only at the corner positions of the element, and adopt linear interpolation in all directions. In the calculation and simulation process of finite element software, the size and density of mesh influence the accuracy and operation speed of finite element analysis. This paper divides the concrete grid size into $5 \mathrm{~mm}$, the steel fiber cell size is set 
TABLE 5: Thermodynamic parameters.

\begin{tabular}{lcccc}
\hline Material & Density $\left(\mathrm{kg} / \mathrm{m}^{3}\right)$ & Conduction of heat $(\mathrm{W}(\mathrm{m} \cdot \mathrm{K}))$ & Swell $\left({ }^{\circ} \mathrm{C}\right)$ & Specific heat $\left(\mathrm{J}\left(\mathrm{kg} \cdot{ }^{\circ} \mathrm{C}\right)\right)$ \\
\hline Concrete & $2.5 e 3$ & 1.28 & $1 e-5$ & $9.6 e 2$ \\
Steel fiber & $7.85 e 3$ & 48 & $1.4 e-5$ & $4.8 e 2$ \\
\hline
\end{tabular}

to $4 \mathrm{~mm}[44,45]$, and the grid division of the structure is shown in Figure 32.

According to the rapid freeze-thaw method, one freezethaw cycle is four hours, and the corresponding time of 100 freeze-thaw cycles is $1.44 e 6 \mathrm{~s}$. The heat transfer analysis step is selected, and the time length is $1.44 \mathrm{e} 6 \mathrm{~s}$. The load changes with time in a quick manner. Set interaction in the analysis step corresponding to transient heat transfer, and select the surface heat exchange conditions. Take the film heat dissipation coefficient, that is, the natural convection heat transfer coefficient of the concrete surface is $100 \mathrm{~W} /\left(\mathrm{m}^{2} \cdot \mathrm{K}\right)$, and set the ambient temperature at $20^{\circ} \mathrm{C}$.

The heat conduction analysis document is post-processed in the static analysis, and the temperature stress simulation diagram of the fiber-reinforced concrete model with $1 \%$ steel fiber content is shown in Figure 33. It can be seen from the temperature change cloud picture of the structural model that the freeze-thaw cycle is a process of heat transfer. The temperature is transferred from the outside to the inside, which is affected by the temperature field. It can be seen from the cloud diagram that the internal temperature lags behind the surface temperature.

Based on the original finite element thermal analysis model, the properties and contact interactions between concrete and steel fiber are defined, and the material parameters of concrete in the model are set, as shown in Table 6. According to the China National Standard Code for Concrete Design (GB 50010-2010) [46], concrete's compressive and tensile properties in the constitutive relation of plastic damage are calculated. Set the dynamic elastic modulus of steel fiber at $200 \mathrm{GPa}$ and Poisson's ratio at 0.31 .

The grid type selects the linear order three-dimensional stress type, the eight-node linear hexahedral element C3D8R, and uses the reduced integration and hourglass control method to calculate. The boundary condition type is displacement/rotation angle in the load setting, and the analysis steps are fixed constraints on the lower surface of the model in the $Z$-axis direction, displacement load on the upper surface in the $Z$-axis direction, and the boundary condition is set to $-10 \mathrm{~mm}$.

The above conclusions reinforce and verify the correct guiding significance of Abaqus, a large-scale finite element software, to freeze-thaw cycle simulation of concrete structures. Furthermore, compared with the experimental modeling process, it can be seen that the stress failure position and failure degree of concrete block with $1 \%$ steel fiber content obtained from the post-processing results of numerical simulation are roughly the same as the experimental results, as shown in Figure 34.

The main reason for time internal temperature stress is that with the continuous development and expansion of micro-cracks, the internal pore water flows to the crack position in freezing and thawing. With the increase and

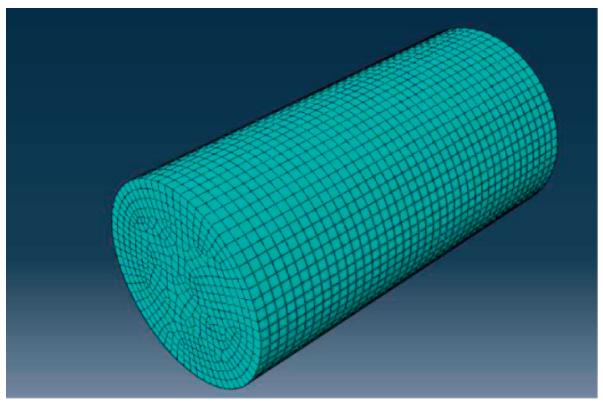

FIGURE 32: Grid division diagram of the structural model.

decrease of temperature, the freezing and expansion of water leads to the further development of structural cracks and finally leads to the destruction of the structural models.

The excellent restoration of compression damage nephogram shows the formation process of internal cracks. At the initial loading stage, the concrete structure is in the linear elastic stage. With the increase of loading time, the superposition of internal deformation accumulation and stress concentration leads to the corresponding tensile strength of weak areas and damage. After that, the new area in the internal unit is damaged and deteriorated, and new cracks are formed. Cracks crisscrossed and developed continuously, causing the specimen to expand laterally, eventually forming inverted splayed cracks from top to bottom, and the structure was completely destroyed. It can also be seen from the nephogram that the damage and deterioration of concrete structure under uniaxial compression are essentially the initial fine lines inside, which develop and expand with the extension of loading time, until it runs through the whole test block structure, resulting in the loss of structural bearing capacity.

The concrete with $0 \%, 1 \%$, and $2 \%$ fiber content extracted from Abaqus post-treatment corresponds to the stress and strain of displacement load after 100 freeze-thaw cycles. Therefore, the stress-strain curves of 100 freeze-thaw cycles are obtained by data processing, as shown in Figure 35.

Concrete is a brittle material composed of coarse and fine aggregates, cement mortar, internal cracks, and pore water. Heteropoly phase system, its strength grade, and applied load together form a stress-strain curve. It is found that the peak point of the stress-strain curve is higher with the increase of fiber content by observing the above curve. With the increase of compressive strength, the frost resistance durability is enhanced, the rising curve is steep, the peak stress increases, and the time to reach the maximum stress lags.

The data processing and comparison between the stressstrain curves of experimental and numerical simulation show that they are consistent with the standard curves. 

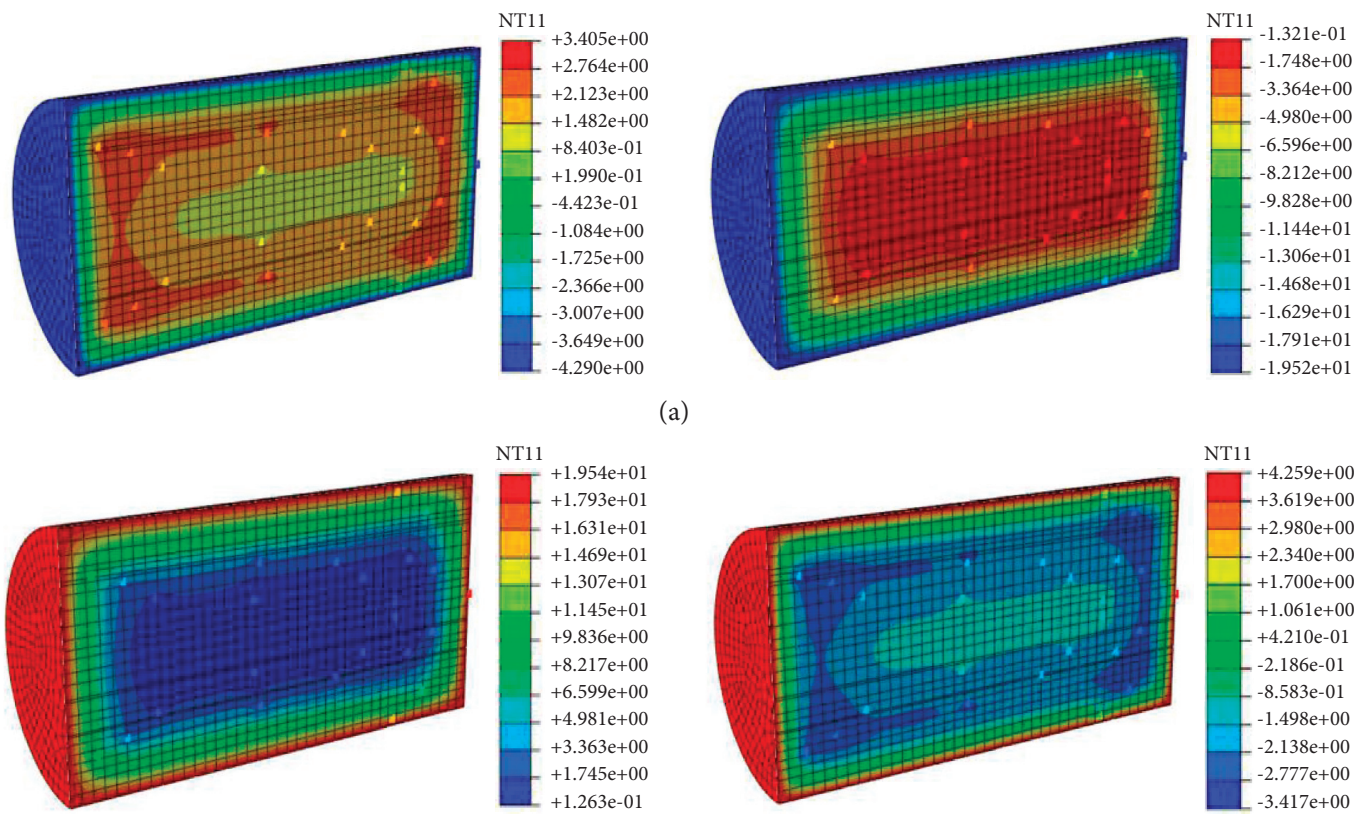

(b)

FIgURE 33: Grid division diagram of structural model. (a) Cloud picture of freezing process change. (b) Cloud picture of melting process change.

TABLE 6: Material parameters.

\begin{tabular}{lcc}
\hline Parameter & Numerical value & Unit \\
\hline Conduction of heat & 1.28 & $\mathrm{~W}(\mathrm{~m} \cdot \mathrm{K})$ \\
Density & $2.5 e 3$ & $\mathrm{~kg} / \mathrm{m}^{3}$ \\
Dynamic modulus of elasticity & $\mathrm{Pa}$ & $-4641 e 10$ \\
Poisson's ratio & 0.2 & - \\
Swell & $1 e-5$ & $1 /{ }^{\circ} \mathrm{C}$ \\
Specific heat & $9.6 e 2$ & $\mathrm{~J}\left(\mathrm{~kg} \cdot{ }^{\circ} \mathrm{C}\right)$ \\
Expansion angle & 38 & - \\
Eccentricity & 0.1 & - \\
$f_{\text {co }} / f_{\text {b0 }}$ & 1.16 & - \\
$K$ & 0.6667 & - \\
Coefficient of viscosity & $1 e-5$ & - \\
\hline
\end{tabular}

DAMAGEC

(平均: $75 \%$ )

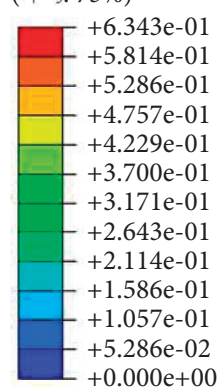

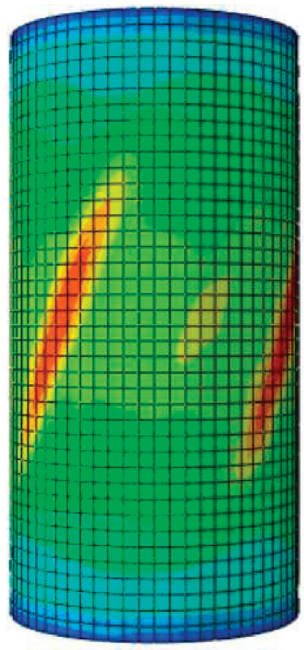

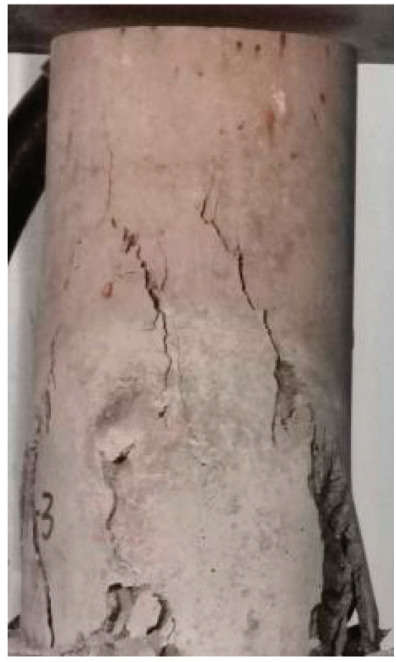

(a)

Figure 34: Continued. 

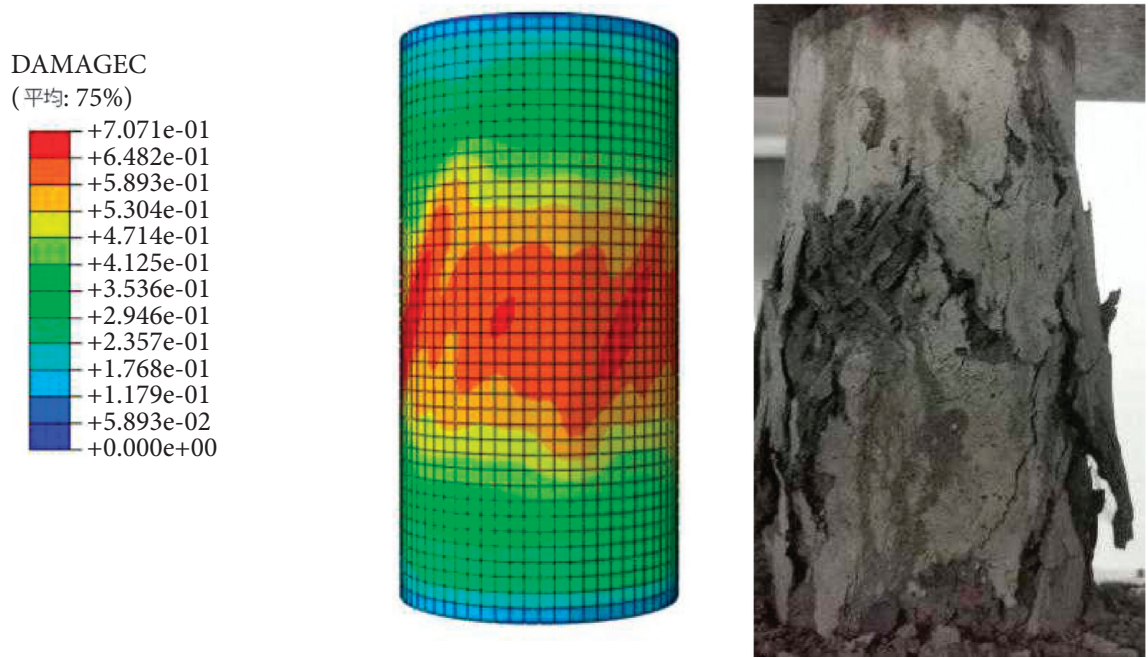

(b)

Figure 34: Comparison diagram between test and modeling. (a) Comparison diagram in applied load. (b) Comparison diagram after loading.

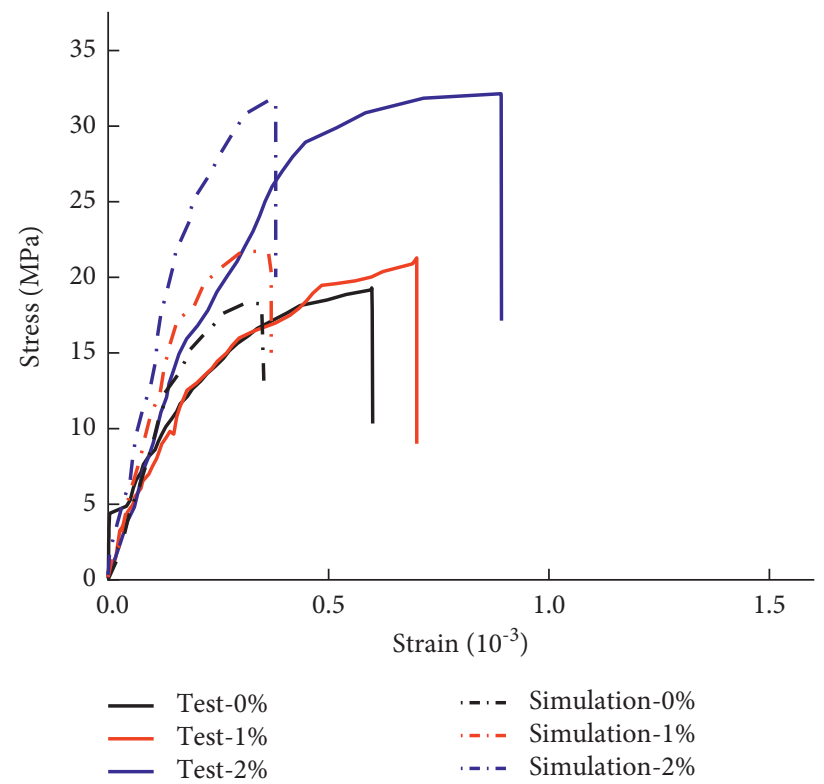

FIgURE 35: Stress-strain comparison diagram.

Moreover, the peak points of experimental curves are more significant than those of numerical simulation, and the delay lags behind the numerical simulation results, so they have similar trends.

\section{Conclusions}

This paper discusses the influence of different environments on the durability of SFRC from two aspects: micromorphology and mechanical properties. The specific conclusions are as follows:

(1) The axial compression test results show that steel fiber can effectively inhibit concrete erosion in an unfavorable environment. Furthermore, adding steel fiber in a hostile environment can improve the compressive strength of concrete from $2.6 \%$ to $69.2 \%$. It has the most obvious influence on concrete in a freeze-thaw environment, enhancing the compressive strength of concrete from $17.6 \%$ to $69.2 \%$ and reducing the strength loss from $0.5 \%$ to $1.3 \%$. Thus, the practical frost resistance of steel fiber-strengthened concrete has an effective improvement.

(2) It can be seen that more cracks existed in surface concrete than core concrete from microstructure observation. The addition of steel fiber can restrain cracks and improve the durability of concrete. Considered with the compressive strength loss, it can be concluded that the environmental damage degree 
of concrete is as follows: freeze-thaw cycle $>$ dilute sulfuric acid $>$ sodium chloride $>$ water $>$ sodium sulfate $>$ sodium hydroxide.

(3) Through numerical simulation analysis, it can be seen that the optimum content of steel fiber is varied concerning different erosion environments. For example, the steel fiber optimum content is $2 \%$ for the freeze-thawing cycle, sulfuric acid, and sodium hydroxide, while $1 \%$ for sodium chloride and sodium sulfate environments.

(4) A simple mechanical compressive strength model of SFRC axial compressive strength under the freezingthawing cycle is proposed, and the validity is verified by experiments results. Furthermore, the finite element software Abaqus is feasible and reliable for simulating and comparing the stress-strain curves of concrete under freeze-thaw cycles.

\section{Data Availability}

All data generated or analysed during this study are included in this published article.

\section{Disclosure}

Wenwen Xu and Qinyuan Zhang are co-first authors.

\section{Conflicts of Interest}

The authors declare that they have no conflicts of interest regarding the publication of this paper.

\section{Authors' Contributions}

Wenwen Xu and Qinyuan Zhang contributed to the work equally.

\section{Acknowledgments}

The authors thank National College Students Innovation and Entrepreneurship Training Program (No. 411120), the 67th Postdoctoral Foundation in China (No. 2020M670872), the Heilongjiang Province Postdoctoral Foundation in China (No. LBH-Z19105), the Fundamental Research Funds from the Central Universities in China (No. 2572019BJ05), and the Heilongjiang Province Studying Abroad Student (Startup Class) Scholarships for their support. Thanks to the Shanghai Harex Steel Fiber Technology Co., Ltd. for sponsoring the steel fiber and Chuanxiong Zhou's help.

\section{References}

[1] S.-W. Choi, J. Choi, and S.-C. Lee, "Probabilistic analysis for strain-hardening behavior of high-performance fiber-reinforced concrete," Materials, vol. 12, no. 15, p. 2399, 2019.

[2] D. Falliano, D. De Domenico, G. Ricciardi, and E. Gugliandolo, "Compressive and flexural strength of fiberreinforced foamed concrete: effect of fiber content, curing conditions and dry density," Construction and Building Materials, vol. 198, pp. 479-493, 2019.
[3] K. Jain and B. Singh, "Deformed steel fibres as minimum shear reinforcement - an investigation," Structures, vol. 7, pp. 126-137, 2016.

[4] P. G. Asteris, H. Naseri, and M. Hajihassani, "On the mechanical characteristics of fiber reinforced polymer concrete," "Advances in concrete construction, vol. 12, no. 4, pp. 271-282, 2021.

[5] Z. C. Shi, Q. T. Su, and C. Y. Dai, "Experimental study on axial tension performance of steel-steel fiber reinforced concrete composite bridge deck," Journal of Building Structures, vol. 40, pp. 47-53, 2019.

[6] G. L. Guo, "Preparation and mechanical properties of steel fiber reinforced concrete," Functional Materials, vol. 51, no. 1, pp. 11165-11170, 2020.

[7] R. Baboo and S. N. Kumar, "Statistical and experimental study to evaluate the variability and reliability of impact strength of steel-polypropylene hybrid fiber reinforced concrete," Journal of Building Engineering, vol. 44, pp. 6-12, 2021.

[8] X. Ming, X. Z. Wang, and H. Tong, "Review on durability of fiber reinforced concrete," Journal of Liaoning University of Technology (Natural Science Edition), vol. 40, no. 1, pp. 35-39, 2020.

[9] W. C. He, X. Q. Kong, and C. Zhou, "Study on mechanical properties and microstructure of steel fiber reinforced recycled concrete," Concrete, vol. 42, no. 12, pp. 44-49, 2020.

[10] L. Feo, F. Ascione, R. Penna, D. Lau et al., "An experimental investigation on freezing and thawing durability of high performance fiber reinforced concrete (HPFRC)," Composite Structures, vol. 234111673 pages, 2020.

[11] J. Fu, "Influence of different fibers on durability and microstructure of high performance concrete," New Building Materials, vol. 47, no. 4, pp. 34-38, 2020.

[12] G. Y. Chai, Z. H. Zhou, and Z. C. Yu, "Experimental study on freeze-thaw of fiber-reinforced concrete," Architecture and Budget, vol. 43, no. 1, pp. 49-53, 2020.

[13] A. Singh, R. Kumar, P. Mehta et al., "Effect of nitric acid on Rice Husk Ash steel fiber reinforced concrete," Materials Today Proceedings, vol. 2020, no. 27, 2020.

[14] F. Y. Liu, W. Q. Ding, and Y. F. Qiao, "Experimental investigation on the tensile behavior of hybrid steel-PVA fiber reinforced concrete containing fly ash and slag powder," Construction and Building Materials, vol. 2020, no. 241, 2020.

[15] S. M. Munqith, K. N. Ayaad, and K. A. Maan, "Flexural behavior of polypropylene fiber reinforced concrete beams with super elastic wire under repeated loading," IOP Conference Series: Materials Science and Engineering, vol. 2021, no. 1, p. 1076, 2021.

[16] G. L. Zhang, J. Xiao, and Z. Ceng, "Summary of the research status of concrete durability," Sichuan Cement, vol. 41, no. 12, pp. 5-6, 2017.

[17] M. H. Liu and Y. F. Wang, "Damage constitutive model of fly ash concrete under freeze-thaw cycles," Journal of Materials in Civil Engineering, vol. 2012, no. 8, pp. 10-16, 2012.

[18] A. Badr, S. Ioannou, and H. Al Maroof, "Effect of rapid hardening cement and setting accelerator on the freeze-thaw durability of fly ash concrete," Key Engineering Materials, vol. 711, pp. 343-350, 2016.

[19] M. M. Islam, M. T. Alam, and M. S. Islam, "Effect of fly ash on freeze-thaw durability of concrete in marine environmen," Australian Journal of Structural Engineering, vol. 2018, no. 10, pp. 25-31, 2016.

[20] Y. L. Wang, Y. F. Zhang, X. Y. Zhang et al., "Experimental study on durability of high performance concrete for railway 
tunnel lining in acid environment," Subgrade Engineering, vol. 2020, no. 6, pp. 118-122+139, 2020.

[21] B. Liu, S. H. Guo, and Q. Zhang, "Experimental study on influencing factors of durability degradation of corroded concrete," Concrete, vol. 41, no. 10, pp. 135-137, 2020.

[22] F. Sun, K. N. Jiang, X. J. Zhu et al., "An alternating experimental study on the combined effect of freeze-thaw and chloride penetration in concrete," Construction and Building Materials, vol. 2020, no. 5, pp. 26-33, 2020.

[23] Y. Luo, D. T. Niu, and L. Su, "Chloride diffusion property of hybrid basalt-polypropylene fibre-reinforced concrete in a chloride-sulphate composite environment under dryingwetting cycles," Materials, vol. 202114 pages, Basel, Switzerland), 2021.

[24] X. W. Fang, Z. K. Lou, Y. L. Gao et al., "Research progress on frost resistance and durability of concrete under sulfate attack," Concrete, vol. 40, no. 12, pp. 6-10+17, 2020.

[25] S. B. Wu, X. S. Wan, T. Yang et al., "Experimental study on mechanical mechanism of concrete under mixed erosion and freeze-thaw cycles," Journal of Nanjing university of Science and Technology, vol. 65, no. 4, pp. 493-500, 2020.

[26] W. L. Qiu, F. Teng, and S. S. Pan, "Damage constitutive model of concrete under repeated load after seawater freeze-thaw cycles," Construction and Building Materials, vol. 2020, no. 2, pp. 36-41, 2020.

[27] F. Galal, H. Mahmoud, and M. Khan, "Fine limestone dust from ornamental stone factories: a potential filler in the production of High-Performance Hybrid Fiber-Reinforced Concrete," Construction and Building Materials, vol. 34, p. 262, 2020.

[28] E. Cuenca, J. Echegaray-Oviedo, and P. Serna, "Influence of concrete matrix and type of fiber on the shear behavior of selfcompacting fiber reinforced concrete beams," Composites Part B: Engineering, vol. 75, no. 75, pp. 135-147, 2015.

[29] K. Watanabe, T. Kimura, and J. Niwa, "Synergetic effect of steel fibers and shear-reinforcing bars on the shear-resistance mechanisms of RC linear members," Construction and Building Materials, vol. 24, no. 12, pp. 2369-2375, 2010.

[30] Y. Ding, Z. You, and S. Jalali, "The composite effect of steel fibres and stirrups on the shear behaviour of beams using selfconsolidating concrete," Engineering Structures, vol. 33, no. 1, pp. 107-117, 2011.

[31] E. Slater, M. Moni, and M. S. Alam, "Predicting the shear strength of steel fiber reinforced concrete beams," Construction and Building Materials, vol. 26, no. 1, pp. 423-436, 2012.

[32] G. Campione, "Flexural behavior of steel fibrous reinforced concrete deep beams," Journal of Structural Engineering, vol. 138, no. 2, pp. 35-246, 2012.

[33] Y. Ji, Y. J. Kim, and Y. Jia, "Performance characterization of plain and CFRP-bonded concrete subjected to sulfuric acid," Materials \& Design, vol. 197, p. 109176, 2021.

[34] L. G. Sorelli, a. Meda, and G. A. Plizzari, "Steel fiber concrete slabs on ground: a structural matter," ACI Materials Journal, vol. 103, no. 4, p. 551, 2006.

[35] A. Caratelli, A. Meda, Z. Rinaldi, and P. Romualdi, "Structural behaviour of precast tunnel segments in fiber reinforced concrete," Tunnelling and Underground Space Technology, vol. 26, no. 2, pp. 284-291, 2011.

[36] H. Dinh, G. J. Parra-Montesinos, and J. K. Wight, Shear Behavior of Steel Fibre Reinforced Concrete Beams without Stirrup Reinforcement, e University of Michigan, Ann Arbor, MI, USA, 2009.
[37] K. Jain and B. Singh, "Steel fibres as minimum shear reinforcement in reinforced concrete beams," Magazine of Concrete Research, vol. 65, no. 7, pp. 430-440, 2013.

[38] K. Jain and B. Singh, "Investigation of steel fibres as minimum shear reinforcement," Proceedings of the Institution of Civil Engineers - Structures and Buildings, vol. 167, no. 5, pp. 285-299, 2014.

[39] Y. T. Trindade, L. A. G. Bitencourt, and O. L. Manzoli, "Design of SFRC members aided by a multiscale model: Part II-Predicting the behavior of RC-SFRC beams," Composite Structures, vol. 241, Article ID 112079, 2020.

[40] C. Karlina, "Influence of fiber variety and content on durability and microstructure of bridge deck high performance concrete," Highway Engineer, vol. 2019, no. 6, pp. 183-190+233, 2019.

[41] C. H. Wang, "Discussion on the technology of strengthening precast bridge deck of channel beam with ultra-high performance concrete," Shanghai Highway, vol. 36, no. 1, pp. 58-61+5, 2018.

[42] Ministry of Housing and Urban-Rural Development of the People's Republic of China, "National Standard (Recommended) of the People's Republic of China: Standard for Test Methods of Long-Term Performance and Durability of Ordinary concrete, China Architecture \& Building Press, Beijing, 2009.

[43] "Ministry of housing and urban-rural development of the People's Republic of China, "state administration of market supervision and administration," National Standard (Recommended) of the People's Republic of China: Standard for Test Methods of Physical and Mechanical Properties of concrete, China Architecture \& Building Press, Beijing, 2019.

[44] Y. X. Zhou, The Dynamic Numerical Simulation Analysis of concrete Freeze-Thaw Environment, Dalian university of technology, Dalian, China, 2019.

[45] W. Y. Wu, Experimental and Numerical Simulation Study on Mechanical Properties of concrete with Different Loading Rates under Freeze-Thaw Cycles, Chang 'an University, Xi'an, China, 2019.

[46] Ministry of Housing and Urban-Rural Development of the People's Republic of China, "National Standard (Recommended) of the People's Republic of China: Code for Design of Concrete, China Architecture \& Building Press, Beijing, 2010. 